\title{
Thermal metamorphic evolution of the Pultusk H chondrite breccia - compositional and textural properties not included in petrological classification
}

\author{
Agata M. KRZESIŃSKA ${ }^{1,2, *}$ \\ 1 Polish Academy of Sciences, Institute of Geological Sciences, Podwale 75, 50-449 Wrocław, Poland \\ 2 Natural History Museum, Department of Earth Sciences, Cromwell Road, London SW7 5BD, United Kingdom
}

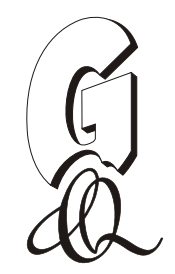

Krzesińska, A.M., 2016. Thermal metamorphic evolution of the Pułtusk $\mathrm{H}$ chondrite breccia - compositional and textural properties not included in petrological classification. Geological Quarterly, 60 (1): 211-224, doi: 10.7306/gq.1267

\begin{abstract}
The thermal history that chondrites experienced on their parent body is an aspect of their petrological classification. However, in the classification scheme, metamorphic conditions are generally limited to the peak metamorphic temperature attained, while it is known that reconstruction of the genuine thermal evolution of any rock requires identification of various metamorphic factors, definition of the temperature-time path during metamorphism and characterization of the processes responsible for heating. Study of the brecciated Pultusk $\mathrm{H}$ chondrite shows that the meteorite comprises both low and high petrologic type material and should be classified as a H3.8-6 chondrite. Based on the textures and mineral and chemical composition, the thermal metamorphic history of the breccia is reconstructed and it is shown to be inconsistent with the petrologic classification; the textural maturation and degree of compositional equilibrium in the meteorite do not correspond to the temperatures attained. The metamorphic conditions are shown to be a function of the primary composition of the accreted minerals and of two metamorphic phases, progressive and retrogressive. First, a prograde phase led to textural maturation and equilibration of the chemical composition of silicates and oxides. The peak metamorphic temperatures were at least $\sim 700^{\circ} \mathrm{C}$ for the type 3.8 . and 4 material, and up to $\sim 1000^{\circ} \mathrm{C}$ in $\mathrm{H} 6$ clasts i.e., sufficient to locally give rise to partial melting. The following retrograde metamorphism led to compositional re-equilibration of minerals and textural re-equilibration of minerals with partial melts. The cooling rate during retrograde metamorphism down to at least $\sim 700^{\circ} \mathrm{C}$ was low, which allowed potassium feldspar to form patches in Na-plagioclase and pseudobrookite-armalcolite breakdown to form an association of ilmenite and rutile. The two-phase metamorphic evolution of the Pultusk breccia was the most likely the result of impact heating, which affected the parent body in its very early history.
\end{abstract}

Key words: $\mathrm{H}$ chondrite, parent body metamorphism, partial melting, spinel group minerals, rutile in chondrites.

\section{INTRODUCTION}

The parent bodies of ordinary chondrites, during accretion and $\sim 60 \mathrm{Ma}$ later, were commonly affected by thermal metamorphism (e.g., Brearley and Jones, 1998; Huss et al., 2006). It is broadly accepted that this process led to attaining equilibrium, both compositional and textural, in the rocks comprising the bodies, i.e. chondrites. Systematic changes in the equilibrium degree and textural maturation in chondrites have been used to develop a classification scheme categorizing chondrites into petrologic types: from 3 (not thermally processed) to 6 (highly metamorphosed; Van Schmus and Wood, 1967; Brearley and Jones, 1998). By definition, the scheme should describe the progression of accretional metamorphism that a particular chondrite type experienced on its parent body. However, large inconsistencies are observed when trying to deduce the thermal

\section{*E-mail: agatakrz@twarda.pan.pl}

Received: August 28, 2015; accepted: November 1, 2015; first published online: December, 17, 2015 evolution of chondritic parent bodies from features of chondrites arranged according to petrological classification scheme (e.g., Lux et al., 1980; Grimm, 1985; Kessel et al., 2007; Kovach and Jones, 2010).

To gain insight into the connection between petrological classification and the early thermal evolution of chondrites, scientific studies have been undertaken by such means as thermochronological constraints (e.g., Pellas and Storzer, 1981; Trieloff et al., 2003; Bouvier et al., 2007), Ar-Ar gas retention measurements (Swindle et al., 2009; Bogard, 2011) or quantifications of metallographic cooling rates (e.g., Scott et al., 2014 and references therein). Unfortunately, none of these provided a clear link and all they show that petrologic types never systematically correlate with any metamorphic factor (e.g., Grimm, 1985; Scott et al., 2014).

To account for the inconsistencies observed, different models of chondritic parent bodies structure were proposed, explaining the differences between petrologic types as caused as a result of their location in the parent body. First, the onion shell model assumes a concentric structure of the body and metamorphic temperature and cooling rate distribution according to depth (Miyamoto et al., 1981; Trieloff et al., 2003; Bouvier et al., 2007; Henke et al., 2012). The other, rubble pile model, introduces a re-arrangement of the body by impact, possibly by cat- 
astrophic distribution and re-assembly (Grimm, 1985; Kessel et al., 2007; Ganguly et al., 2013; Scott et al., 2014). Neither model is, however, fully satisfactory.

One of the weakest points of the classification scheme (Van Schmus and Wood, 1967) is that the parameters used there are broadly qualitative (e.g., chondrule appearance) and, more important, arbitrary in terms of genetically linking them to particular metamorphic processes (e.g., plagioclase grain size, low-Ca pyroxene crystallographic structure; see e.g., Buseck and Iljima, 1975). Thus, many inconsistencies reported when petrological classification is applied as a direct proxy of chondrite metamorphic evolution may be a simple result of hidden ambiguities of texture interpretation.

The Pułtusk chondrite fell in 30th of January 1868. It was one of the biggest falls of stony meteorites observed, with $276 \mathrm{~kg}$ of material recovered. It is assigned as H5 (Van Schmus and Wood, 1967), but from the first studies, it was known to be a brecciated, veined chondrite, and many reports noted that it contains H4 and H5 type material (Binns, 1968; Manecki, 1972; Siemiątkowski, 2004).

The aim of the work presented here is two-fold. Firstly, it is focused on a detailed description of the Pultusk breccia and the reclassification resulting from this. Systematic study of this meteorite enabled documentation within it of unequilibrated inclusions, and also of clasts that had partially melted. Secondly, the wide spectrum of petrologic types observed in the breccia permitted inquiry into the conditions that the rock was metamorphosed in, and to semi-quantitatively constrain the temperature-time path it experienced. This is important, as it links textural features of the chondrite to various metamorphic conditions and factors, an aspect that has received little attention so far (e.g., Lux et al., 1980; Kessel et al., 2007; Kovach and Jones, 2010; Tait et al., 2014; Guignard and Toplis, 2015). Reconstruction of metamorphic evolution of the Pultusk chondrite may shed some light on parameters not covered by the petrological classification scheme (Van Schmus and Wood, 1967).

\section{SAMPLES AND METHODS}

The research was conducted based on mesoscopic recognition of 599 samples of the Pultusk meteorite and further detailed analysis of thin sections prepared from selected specimens.

SAMPLES

The samples come from the collections of the S.J. Thugutt Geological Museum of the Faculty of Geology (University of Warsaw); the Geological Museum at the Institute of Geological Sciences PAS in Kraków; the Museum of the Earth, Polish Academy of Sciences in Warsaw; the Mineralogical Museum at the University of Wrocław; and the Museum of Geological Sciences at the Jagiellonian University in Kraków and from the Institute of Geological Sciences, Polish Academy of Sciences. The sample weights range from 1.9 to $8100 \mathrm{~g} .23$ thin sections were prepared from selected samples and were further studied by optical and electron microscopy.

\section{METHODS}

Petrologic types of the chondritic rock fragments were assigned according to the scheme of Van Schmus and Wood (1967), with special attention to chondrule appearance, plagioclase grain size and compositional homogeneity of the minerals. Data on phase composition were collected by Electron Microprobe measurements with a $3 \mu \mathrm{m}$ focussed electron beam applied. The analyses were obtained on Cameca $S X-100$ at the Laboratory of Electron Microanalysis, State Geological Institute of Dionýz Štúr, Bratislava, Slovak Republic and Cameca SX-100 at the Institute of Geochemistry and Petrology, Warsaw University. In both cases, beam current was set on $20 \mathrm{nA}$, and accelerating voltage of $15 \mathrm{keV}$ was chosen for analyses of silicate oxide and sulfide minerals, and $20 \mathrm{keV}$ for native alloys. Counting times of up to $10 \mathrm{~s}$ per element were used for all but $\mathrm{Zn}$ analysed. For $\mathrm{Zn}$ in spinel group minerals counting time was set on $60 \mathrm{~s}$, in order to minimize the matrix effect. Natural and synthetic standards were used to transform count rates into element concentrations in all measurements. For native FeNi alloy and sulfide analyses calibration on $\mathrm{GaP}$ for $\mathrm{P}$, pyrite for Fe, chalcopyrite for $\mathrm{Cu}$ and $\mathrm{S}$, sphalerite for $\mathrm{S}, \mathrm{Ni}$ for $\mathrm{Ni}$, and Co for Co were applied. For analyses of silicates the following standards were used: $\mathrm{Na}$ calibrated on albite, $\mathrm{Ca}$ on wollastonite, $\mathrm{Mg}$ on forsterite, $\mathrm{Fe}$ on fayalite, $\mathrm{Mn}$ on rodonite, $\mathrm{Si}$ and $\mathrm{K}$ on orthoclase, $\mathrm{Al}$ on corundum, $\mathrm{Ti}$ on rutile, $\mathrm{Cr}$ on $\mathrm{Cr}, \mathrm{Ni}$ on $\mathrm{Ni}$, and $\mathrm{Co}$ on $\mathrm{Co}$. Oxide mineral analyses were collected with the set of standards as for silicates with the addition of willemite for $\mathrm{Zn}$ and $\mathrm{V}$ for $\mathrm{V}$. The procedure of $\mathrm{X}$-Phi correction (Merlet et al., 2003) was applied to correct existing peak overlaps. For analyses of $\mathrm{Fe}$,Ni native alloys, additional correction was done to remove interference of the $\mathrm{Fe}-\mathrm{K} \beta$ peak on the Co-K $\alpha$ peak.

Electron Microprobe (EMP) analyses were further used to calculate equilibration temperatures of silicate and oxide minerals on the basis of the olivine-spinel thermometer (Sack and Ghiorso, 1991). The thermometer is based on Fe-Mg partitioning between olivine and spinel and it was shown to be a relevant tool for analysis of equilibration temperatures of terrestrial and chondritic rocks (e.g., Irvine, 1965; Kessel et al., 2007). The correction of Wlotzka (2005) for high chromium content in spinel was here applied and the thermometer equation was as follows:

$$
T\left[{ }^{\circ} \mathrm{C}\right]=\frac{5099 * Y_{C r}+917}{\ln K_{D}+0.282+2.402 * Y_{C r}}-273
$$

where: $K_{D}$ - olivine and spinel $\mathrm{Mg}$ and Fe distriution coefficient:

$$
K_{D}=\frac{\mathrm{Mg}_{\mathrm{ol}}}{\mathrm{Fe}_{\mathrm{ol}}} \times \frac{\mathrm{Fe}_{\mathrm{sp}}}{\mathrm{Mg}_{\mathrm{sp}}} ;
$$

$\mathrm{Y}_{\mathrm{Cr}}-$ mole ratio $\mathrm{Cr} /(\mathrm{Cr}+\mathrm{Al})$ in spinel.

Thermometric calculations were done for pairs of olivine and chromite contacting with each other, and chromite grains abutted kamacite and met the conditions: $\mathrm{SiO}_{2}$ content below 0.5 wt. $\%, \mathrm{Fe}_{2} \mathrm{O}_{3}$ content below 3 wt. $\%\left(<0.5 \mathrm{Fe}^{3+}\right.$ cation for 24 cations in spinel formula unit), $\mathrm{TiO}_{2}$ below 2 wt. $\%$.

\section{RESULTS}

\section{BRECCIATION OF THE CHONDRITE}

Most of the Pultusk samples are complex breccias. The most distinct aspect of brecciation of the meteorite is the presence of black-coloured zones rich in broken and crushed, cataclased lithic fragments (Fig. 1), formed due to late, 

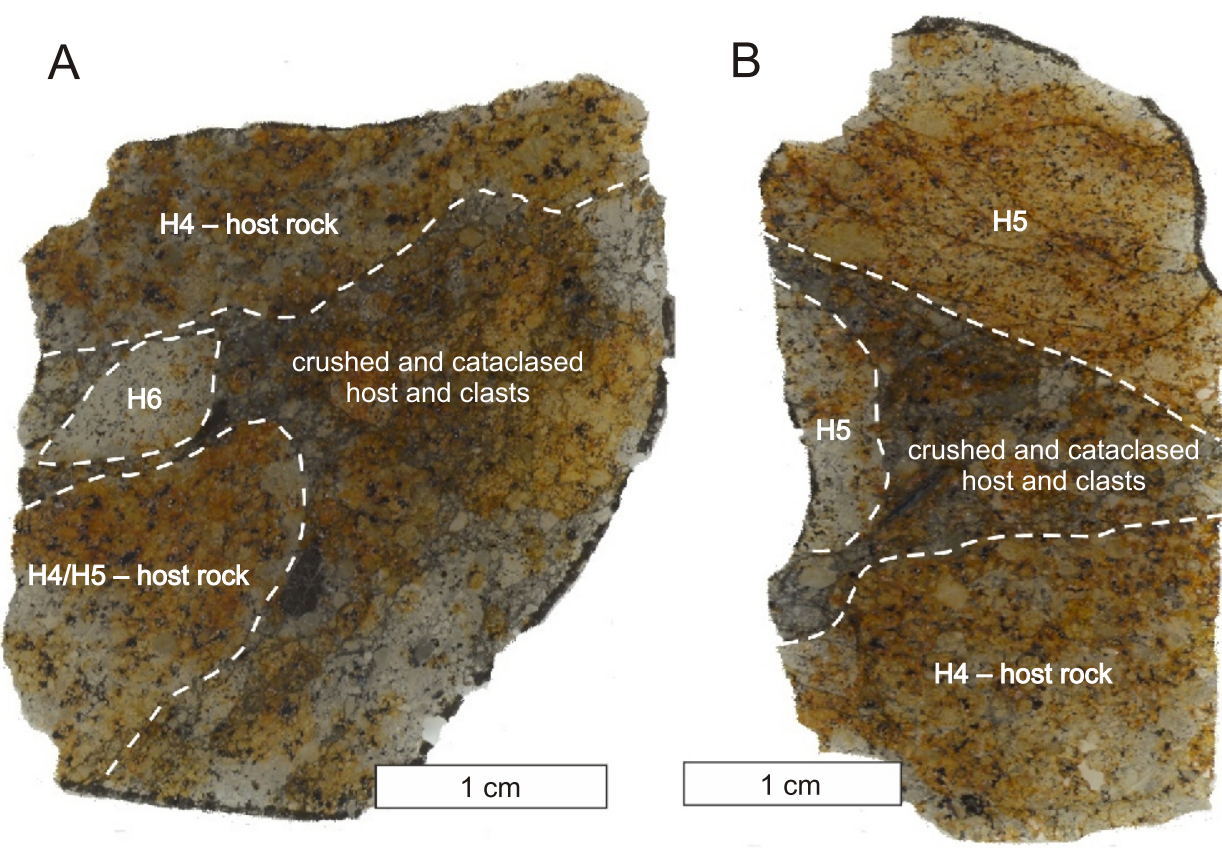

Fig. 1. Brecciated specimens of the Pultusk meteorite

A - host rock of $\mathrm{H} 4 / 5$ type cut by cataclstic zone bearing $\mathrm{H} 6$ clast; $\mathbf{B}$ - host rock cut by cataclastic zone, which bears $\mathrm{H} 5$ clasts; the $\mathrm{H} 5$ clast in the top part of the image is likely enclosed in the cataclastic zone, although the relationship is not shown, this is because of the clast's size extending the size of the fragment most likely; host rock, cataclastic zones and clasts embedded in the zones are marked

post-accretional impact events (Krzesińska and Fritz, 2014; Krzesińska et al., 2015), the textures and processes which are beyond the scope of this paper.

Among the light-coloured material, two type of rock may be distinguished. First, a fine-grained rock with well-delineated chondrules represents the host and comprises $56.4 \%$ of the specimens (Table 1). The second type of material is made of lithic fragments (of various textures and with a high degree of recrystallisation). Very rare relic chondrules are visible in them with the naked eye. The clasts are oval in shape, $0.7-1.5 \mathrm{~cm}$ in size, and the largest one reaches $1.1 \times 2.2 \mathrm{~cm}$. These clasts are always enclosed in the above-mentioned dark-coloured products of deformation. This type of material constitutes $10.9 \%$ of the Puttusk rock (Table 1 and Fig. 1).

Optical microscopy shows that the host rock and clasts differ greatly from each other in chondrule appearance, degree of recrystallisation of matrix and mesostasis material, plagioclase grain size and structure of low-Ca pyroxene. Some differences in

Table 1

Unequilibrated and equilibrated petrologic type rocks of the Pultusk chondrite and their volume $\%$ amount

\begin{tabular}{|l|c|c|}
\hline \multicolumn{2}{|c|}{ Surface analysed: $96 \mathrm{~cm}^{2}\left(9593 \mathrm{~mm}^{2}\right)$} & {$[\%]$} \\
\hline Unequilibrated material & $\mathrm{H} 3.8$ & $<0.1$ \\
\hline Host rock & $\mathrm{H} 4 / \mathrm{H} 5$ & 56.4 \\
\hline Clasts & $\mathrm{H} 5$ & 8.2 \\
\hline Clasts & $\mathrm{H} 6$ & 2. \\
\hline $\begin{array}{l}\text { Products of impact deforma- } \\
\text { tion and crushing of all the pet- } \\
\text { rologic types }\end{array}$ & 32.7 \\
\hline $\begin{array}{l}\text { Calculations done on the surface of } 96 \mathrm{~cm}^{2} \text { i.e., total area of all } \\
\text { the cut meteorite specimens included in the study }\end{array}$ \\
\hline
\end{tabular}

chemical composition of the main mineral phases are observed in the host rock and clasts. Moreover, in the host rock, inclusions rich in spinel group minerals are present (Table 1). The inclusions differ strongly from the host in retaining zonal, unequilibrated composition of minerals. The inclusions are $\sim 500$ $\mu \mathrm{m}$ across, they have rather blurred boundaries and they constitute a very minor fraction of the meteorite $(<0.1 \%$; Table 1$)$.

Detailed inspection of the fragments recognized clearly shows that they represent different petrologic types in the classification of Van Schmus and Wood (1967) and were formed due to diverse thermal processes.

The Pułtusk chondrite is weakly-moderately shocked (S3 shock degree in the classification of Stöffler et al., 1991). It reveals irregular and minor planar fracturing in olivine grains, undulose light extinction in plagioclase and the presence of localized shock melt pockets. Among the suite of samples analysed it appears that rock defined as host is slightly less shock-deformed (S2 degree) than the equilibrated clasts (S3 degree). The most important observation for this research is that the shock event in the Pultusk chondrite is recorded mainly as brittle fractures (Krzesińska et al., 2015) and apart from localized melt pockets it did not cause melting nor lead to compositional changes. Thus, the mineralogy of the meteorite is assumed to be not affected by late shock processes and serves as a proxy for earlier, accretional history.

\section{H4/H5 TYPE HOST ROCK - TEXTURE AND COMPOSITION}

The host portion of the Pultusk chondrite consists usually of well-defined and well-represented chondrules (Fig. 2A), usually 300-700 $\mu \mathrm{m}$ across. In many of them, polysynthetically twinned low-Ca pyroxene crystals are present (Fig. 2B), along with a very fine-grained feldspatic groundmass. At the contacts of pyroxene grains and chondrule mesostasis, tiny (30-60 $\mu \mathrm{m}$-sized) diopside microcrystals occur (Fig. 2C). 

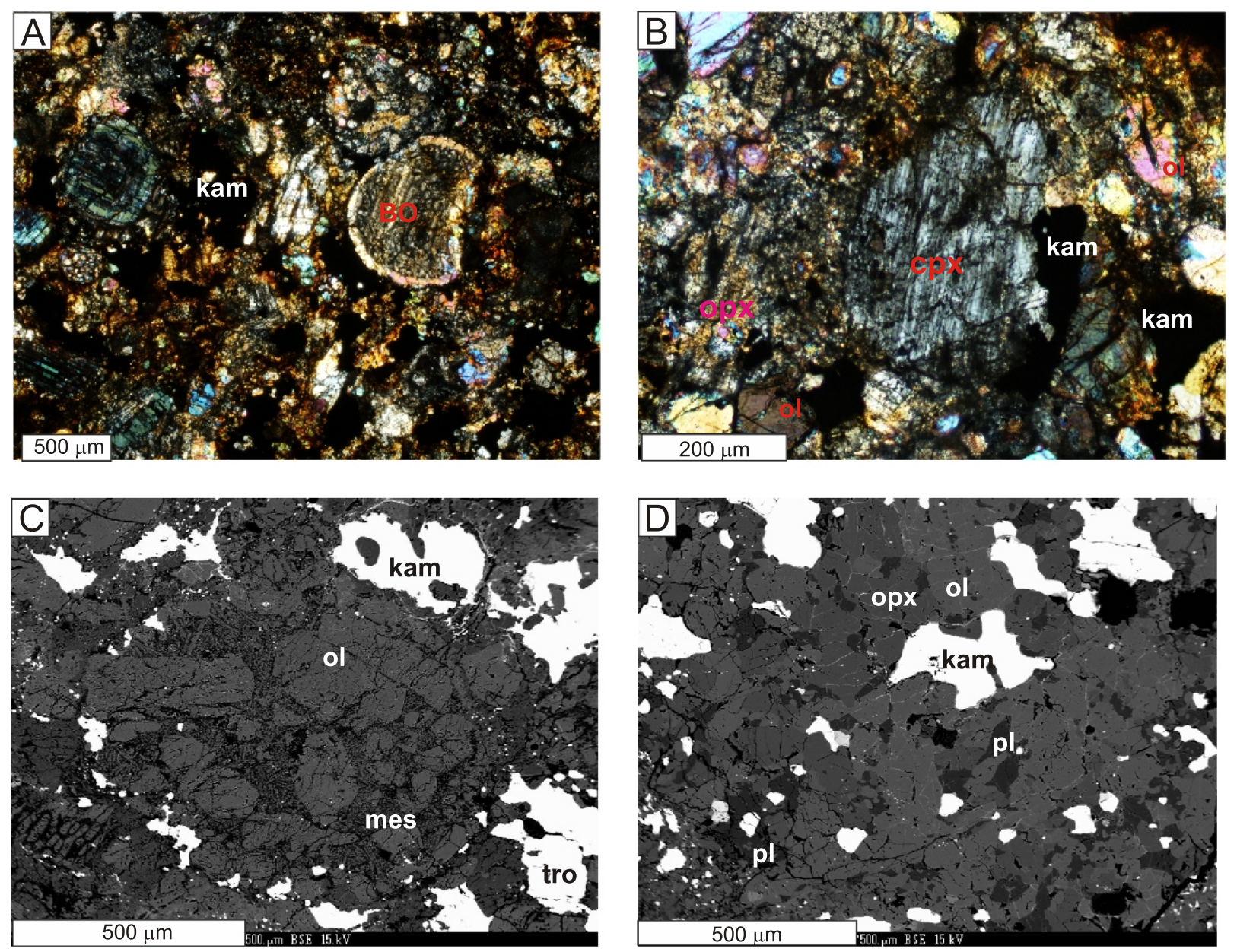

Fig. 2. Textures of the Pułtusk host rock

A - well-distinguished chondrules and fine-grained matrix, photomicrograph, crossed polars; B - twinned crystal of low-Ca pyroxene of monoclinic structure, photomicrograph, crossed polars; C - chondrule with devitrified glassy and cryptocrystalline mesostasis and micorcrystallites of diopside in the host part classified into type 4, BSE image; D - fully crystalline part of the host classified into type 5, isolated plagioclase grains up to $50 \mu \mathrm{m}$ in size are present, BSE image; BO - chondrule with barred olivine structure, $\mathrm{cpx}-$ low-Ca clinopyroxene, kam - kamacite, mes - mesostasis, ol - olivine, opx - low-Ca pyroxene, pl - plagioclase, $\operatorname{tr}$ - troilite

The matrix of the rock is composed of a mixture of isolated grains and cryptocrystalline or very fine-grained feldspathic material (Fig. $2 \mathrm{~A}-\mathrm{C}$ ). It contains anhedral-subhedral, 20-80 $\mu \mathrm{m}$-sized (and up to $750 \mu \mathrm{m}$ ) olivine grains and 20-60 $\mu \mathrm{m}$ long (sporadically up to $650 \mu \mathrm{m}$ ), anhedral low-Ca pyroxene crystals. The pyroxene is represented by both monoclinic and orthorhombic polymorphs (as recognized optically). Olivine is homogeneous in major and minor element composition (18.8 \pm 1.2 mol\% of $\mathrm{Fa} ; 0.35-0.59 \mathrm{wt} . \% \mathrm{MnO}$ and no other detectable minor elements; Fig. 3B and Appendix $1^{*}$ ). Low-Ca pyroxene has a composition of: $\mathrm{En}_{80.8-83.8} \mathrm{Fs}_{14.6-18.3}$ $\mathrm{Wo}_{0.3-3.2}$, but as compared to olivine it is compositionally more heterogeneous (Appendix 2). Diopside has a composition of $\mathrm{En}_{47.2-49.6} \mathrm{Fs}_{5.5-6.3} \mathrm{Wo}_{44.6-46.4}$ (Appendix 3).

Accessory oxide minerals are subhedral chromite and ilmenite, $20-90 \mu \mathrm{m}$ in size. Chromite is predominantly compositionally homogeneous, however, some grain to grain variability is observed. In general, chromite reveals a narrow range of composition both between and inside grains. Atomic ratios $\mathrm{Cr} /(\mathrm{Cr}+\mathrm{Al})(\mathrm{Cr}$, hereafter) and $\mathrm{Fe} /(\mathrm{Fe}+\mathrm{Mg})(\mathrm{Fe} \#$, hereafter) are $0.83-0.84$ and $0.81-0.82$, respectively (Fig. 4). Some grains, however, reveal lower values of $\mathrm{Cr} \#$ and $\mathrm{Fe \#}$, down to 0.68 and 0.67 , respectively (Fig. 4 ), being rather spinelian chromites. Both chromite and spinelian chromite grains are rich in $\mathrm{MnO}$ (0.65-1.12 wt.\%), $\mathrm{ZnO}\left(0.13-0.55\right.$ wt.\%) and $\mathrm{TiO}_{2}$ (1.15-2.45 wt.\%), the content of which is correlated to Fe\# (Appendix 4). Ilmenite is homogeneous and it contains slight enrichment of pyrophanite (Mn-particle; 5-6 mol\%), and geikielite (Mg-particle; 15-17 mol\%; Appendix 5).

FeNi-metal and troilite form irregular, 10-240 $\mu \mathrm{m}$ large (and up to $1000 \mu \mathrm{m}$ ) aggregates. The predominant native metal is kamacite (4.96-6.69 wt.\% Ni; 0.35-0.58 wt.\% Co), which coexists with lamellar tetrataenite (48.2-51.8 wt.\% Ni, $0.05-0.13$ wt. $\%$ Co and $0.35-0.38$ wt. $\% \mathrm{Cu}$ ). Isolated grains of zoneless taenite (21.10-42.65 wt.\% Ni, 0.10-0.22 wt.\% Co and $0.14-0.21$ wt. \% Cu) are also frequent. For all the FeNi-minerals a strong negative correlation of $\mathrm{Co}$ and $\mathrm{Ni}$ content is observed (Fig. 5 and Appendix 6), as well as a positive correlation of $\mathrm{Cu}$ and $\mathrm{Ni}$ content.

The interstitial feldspathic mass is glassy or very fine-grained, and in places becomes devitrified and crystalline; anhedral plagioclase grains are 5-10 $\mu \mathrm{m}$-sized. Both the 

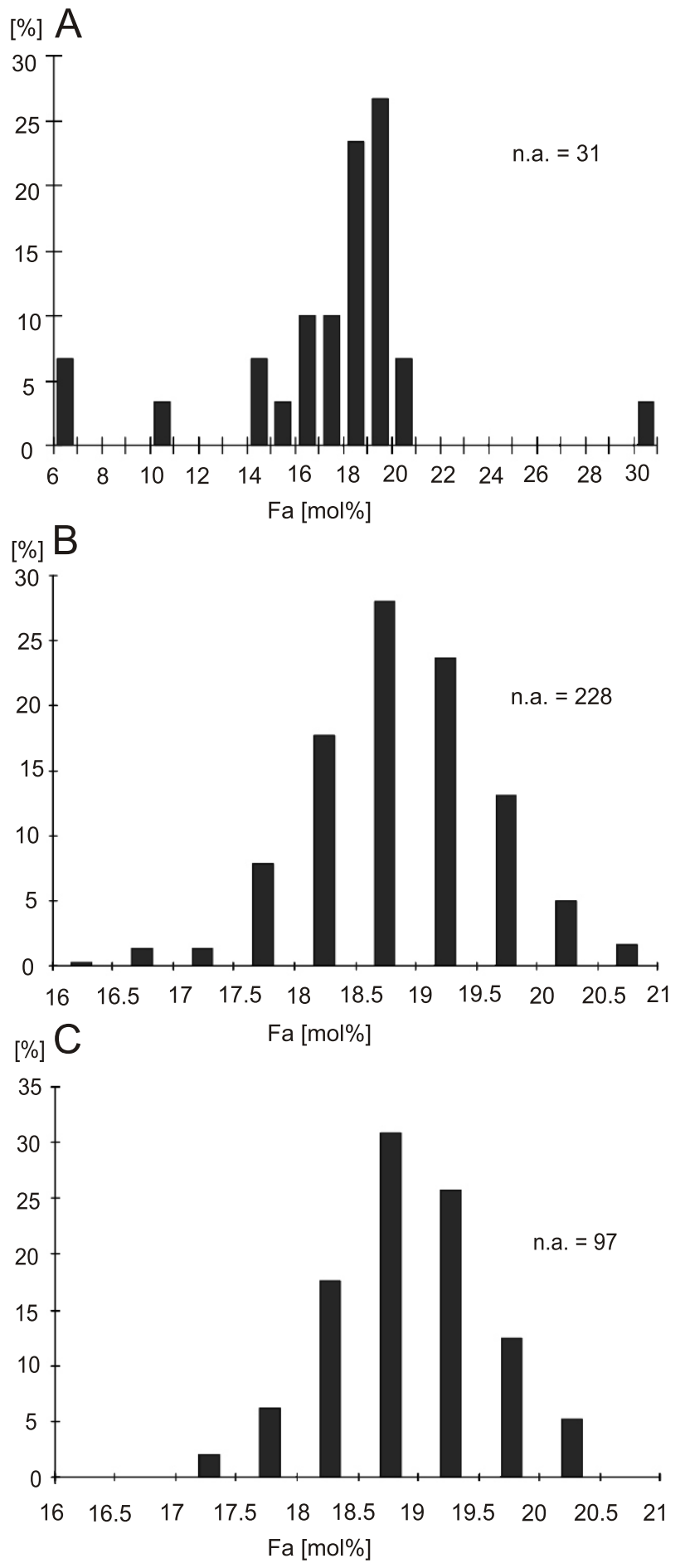

Fig. 3. Histograms of the compositional distribution of olivine grains based on EMP data

A - olivine in spinel-bearing inclusions $\mathrm{H} 3.8$; $\mathbf{B}$ - olivine in the host $\mathrm{H} 4 / \mathrm{H} 5$; $\mathbf{C}$ - olivine of the equilibrated clasts $\mathrm{H} 5$ and $\mathrm{H} 6$; n.a. - number of analyses

feldspathic microcrystalline mass and individual plagioclase crystals have a quite uniform composition of albite-oligoclase: $\mathrm{Ab}_{75.6-87.1} \mathrm{An}_{5.6-17.9} \mathrm{Or}_{3.6-9.6}$ (Fig. 6 and Appendix 7).

Textural features of the host rock change from place to place and in some cases chondrules are very well-defined, while in many other they appear blurred with very diffuse boundaries (Fig. 2C vs. Fig. 2D).
H5 AND H6 TYPE, HIGHLY EQUILIBRATED CLASTS

The recrystallised, light-colored clasts, which are embedded in darkened, cataclastic zones differ texturally and compositionally from the host rock (Fig. 1). Moreover, the crystallinity degree and textures differ among the clasts. Some differences in chemical composition of mineral may be also observed, which are accompanied by an increase in the textural maturation of the clasts.

H5 type texture. In one kind of clasts (H5 type rock, hereafter) chondrule relicts are detected, however, as compared to the host rock, they are highly blurred and recrystallised (Fig. 7A). Olivine and low-Ca pyroxene form anhedral-subhedral, 40-90 $\mu \mathrm{m}$-sized (up to 250-300 $\mu \mathrm{m}$ ) crystals. Most contacts between olivine and orthopyroxene form $\sim 120^{\circ}$ triple junctions. Subhedral-anhedral chromite and ilmenite grains are larger than the host oxides i.e., they are $70-150 \mu \mathrm{m}$ in size and even larger crystals $(>150 \mu \mathrm{m})$ are quite common. Both chondrule mesostasis and matrix are fully crystalline, composed of 15-40 $\mu \mathrm{m}$-sized, anhedral plagioclase crystals interstitial to olivine and pyroxene (Fig. 7B). Individual plagioclase grains are up to $90 \mu \mathrm{m}$ in size. Opaque minerals in the matrix form isolated, anhedral, irregularly shaped grains.

H6 type texture. The other type of clasts (H6 type rock, hereafter) differs from the former ones in that chondrule relicts are absent, and the chondritic structure is almost obliterated (Fig. 8). Olivine and opx crystals form triple junctions, but additionally in places reveal a bimodal grain size distribution, with individual large grains $(80-200 \mu \mathrm{m})$ embedded in a fine-grained mass $(20-40 \mu \mathrm{m})$. Large orthopyroxene grains often poikilitically enclose olivine (Fig. 8A, B).

The plagioclase forming the matrix of the clasts is fully crystalline. The crystals are lobate in shape, $50-90 \mu \mathrm{m}$, or sporadically up to $200 \mu \mathrm{m}$ in size. In some places, it appears that plagioclase crystals form a network, which interstitially encloses randomly distributed tiny olivine and orthopyroxene grains (Fig. 8A, B). Plagioclase is very often polysynthetically twinned, and twinning seems to continue in grains next to each other. Also, large (up to $150 \mu \mathrm{m}$ in size) rounded grains of FeNi-metal and troilite are encapsulated in interstitial plagioclase, usually in the widest parts of interstices (Fig. 8A, B). A characteristic feature of this material is that the olivine crystals enclosed in plagioclase interstices have rounded corners (Fig. 8A) and large olivine crystals outside the interstices are often curved-in at the contact with the plagioclase (Fig. 8B).

IImenite crystals, although generally not differing from type 5 ilmenites, in individual cases are associated with rutile, forming 5-10 $\mu \mathrm{m}$ blebs or 3-10 $\mu \mathrm{m}$ wide lamellae (Fig. 8D). Ilmenite then contacts with FeNi-metal.

Composition of minerals in the clasts. Both types of recrystallised clasts represent rock that is chemically well-equilibrated. The chemical composition of the silicates does not vary significantly; olivine composition peaks at $18.9 \pm 0.9 \mathrm{~mol} \% \mathrm{Fa}$ (Fig. 3C and Appendix 1), and orthopyroxene is homogeneous $\mathrm{En}_{80.4-83.7} \mathrm{Fs}_{14.9-18.1} \mathrm{Wo}_{0.9-1.7} . \mathrm{CaO}$ content in orthopyroxene is generally low, but in some crystals in $\mathrm{H} 6$ type clasts it reaches up to 0.88 wt.\% (Appendix 2).

Crystalline plagioclase in the matrix of clasts is compositionally similar to glass in the host rock: $A b_{81.0} A n_{12.2} \mathrm{Or}_{5.7}$. In type 6 clasts, plagioclase grains in particular interstices are compositionally homogeneous, but some differences may be observed between interstices. The rim parts of some interstitial plagioclase crystals contain alkali feldspar patches $\left(A b_{10.0} A n_{6.5} \mathrm{Or}_{83.5}\right)$. The content of $A n$ in the patches is rather constant, while the content of Or may vary (Fig. 6 and Appendix 7). 

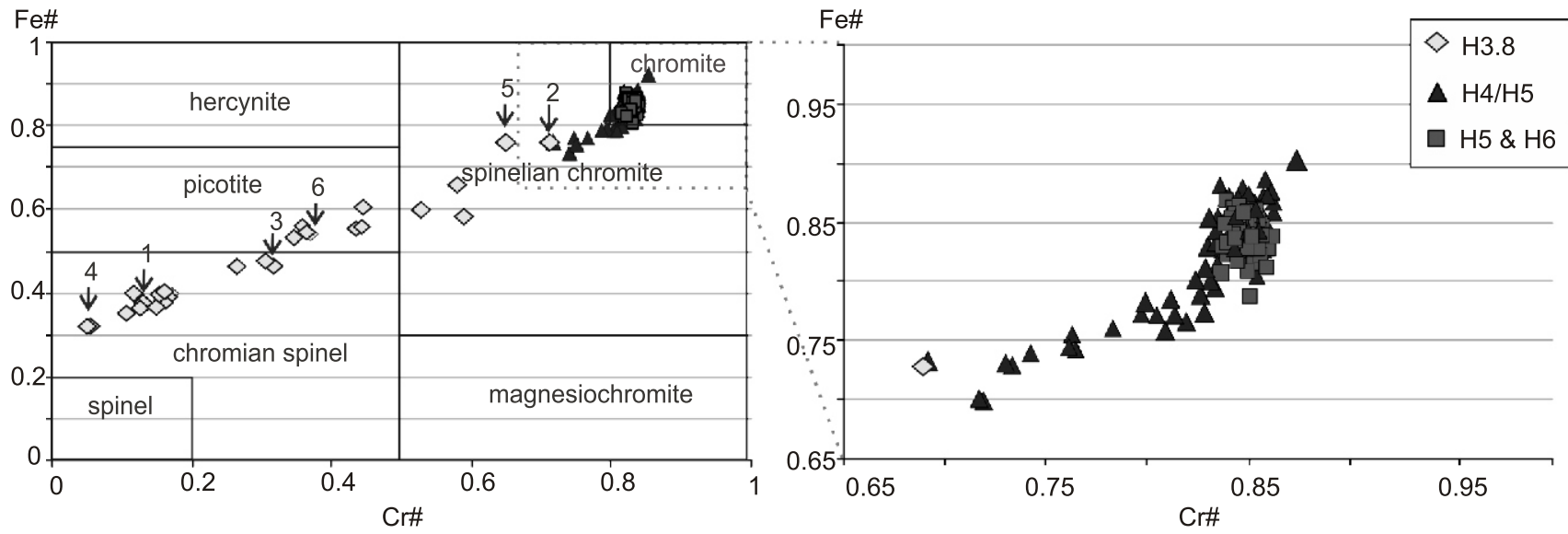

Fig. 4. Plot of atomic $\mathrm{Fe} /(\mathrm{Fe}+\mathrm{Mg})$ and $\mathrm{Cr} /(\mathrm{Cr}+\mathrm{Al})$ ratios of spinel group minerals in the Pultusk H4/H5 host rock, $\mathrm{H} 5$ and $\mathrm{H} 6 \mathrm{clasts}$ and inclusions of unequilibrated rock $\mathrm{H} 3.8$

Ferric iron in spinel group minerals is negligibly low; spinels of spinel-bearing inclusions vary widely in composition, but all the atomic ratios form a trend line; numbers with arrows relate to point analyses of zonal spinel grains in H3.8 inclusions (marked in Fig. 10)

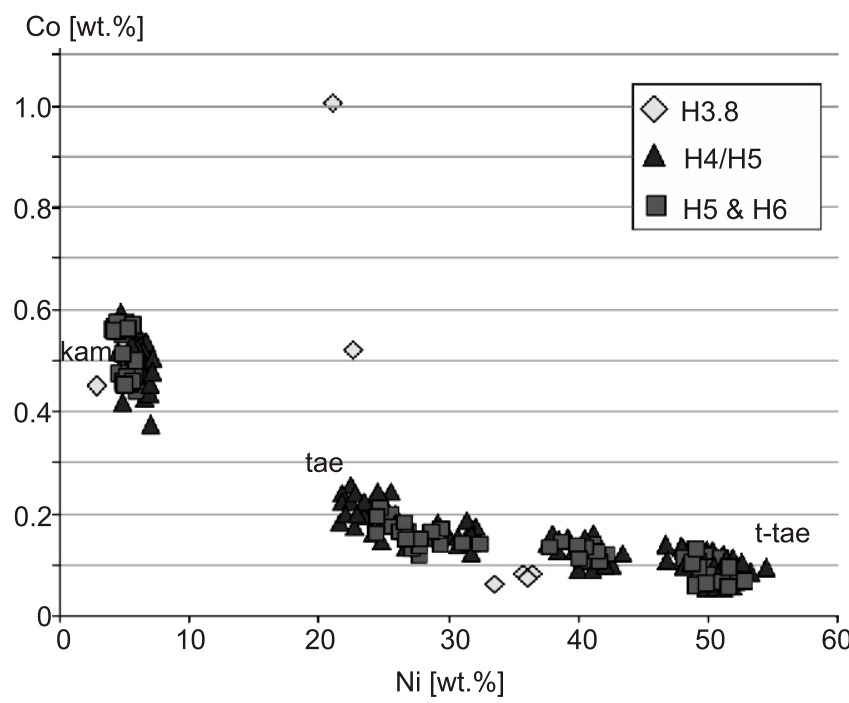

Fig. 5. FeNi-metal composition in the Pułtusk host chondritic rock $\mathrm{H} 4 / \mathrm{H} 5$, clasts $\mathrm{H} 5$ and $\mathrm{H} 6$ as well as $\mathrm{H} 3.8$ spinel-bearing inclusions

tae - taenite or disordered FeNi phase with Ni content in the range of 20-35 wt.\%; t-tae - tetrataenite; other explanations as in Figure 2

Spinel group minerals are highly homogeneous and only pure chromite occurs. The homogeneous composition of this mineral is manifested by very narrow ranges of $(\mathrm{Cr} \#)$ and $(\mathrm{Fe \#})$ : 0.84-0.86 and 0.84-0.87, respectively (Fig. 4 and Appendix 4). IImenite is enriched in pyrophanite $(6 \mathrm{~mol} \%)$ and geikielite (16 mol\%). When associated with rutile in type 6 material, ilmenite reveals higher enrichment in $\mathrm{MnO}$ (25 mol\% of pyrophanite) and strong depletion in $\mathrm{FeO}$ (56 mol\% Fe particle) (Appendix 5).

Among FeNi-rich minerals, kamacite accompanied by tetrataenite dominates. Zoneless taenite also occurs, but is much less abundant than in the host rock. Ni content in the kamacite is lower (4.52-6.86 wt.\%) than in the host rock and $\mathrm{Ni}$ content in tetrataenite (46.72-52.22 wt.\%) is higher. Similarly to

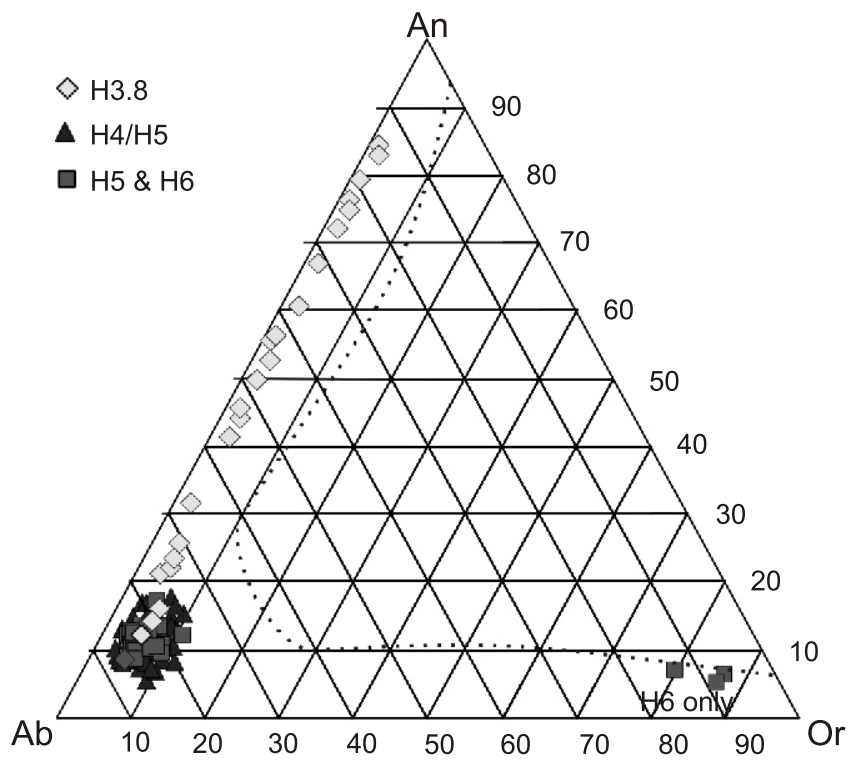

Fig. 6. Ternary diagram for Ab-An-Or molar content of feldspathic glass and plagioclase crystals in the $\mathrm{H} 4 / \mathrm{H} 5$ host rock, clasts $\mathrm{H} 5$ and $\mathrm{H} 6$ as well as $\mathrm{H} 3.8$ inclusions

the host rock, cobalt and copper amounts in FeNi-metal minerals correlate with the nickel content (Fig. 5 and Appendix 6).

\section{OLIVINE-SPINEL EQUILIBRATION TEMPERATURES OF THE HOST ROCK AND THE CLASTS}

Both the host rock and the clasts are certainly well-equilibrated rocks, and the olivine-spinel thermometer (Sack and Ghiorso, 1991; Wlotzka, 2005) was applied to calculate the temperatures they were equilibrated in. Olivine and chromite considered for calculations reveal homogeneous compositions and no chemical zoning was observed in them. The calcula- 

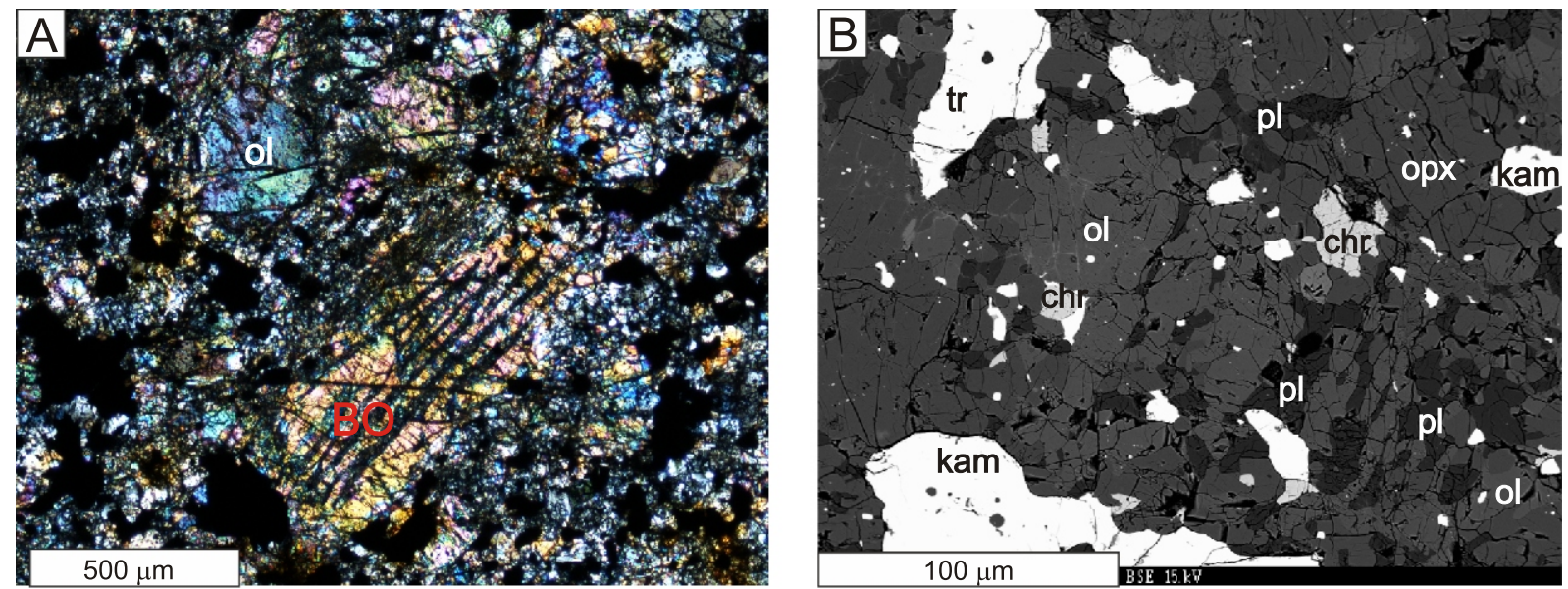

Fig. 7. Textures of equilibrated $\mathrm{H} 5$ clasts

A - relict chondrule embedded into crystalline matrix, photomicrograph, crossed polars; B - crystalline matrix with blurred crystal boundaries and plagioclase grains $\sim 10-50 \mu \mathrm{m}$ in size, BSE image; chr - chromite, other explanations as in Figure 2
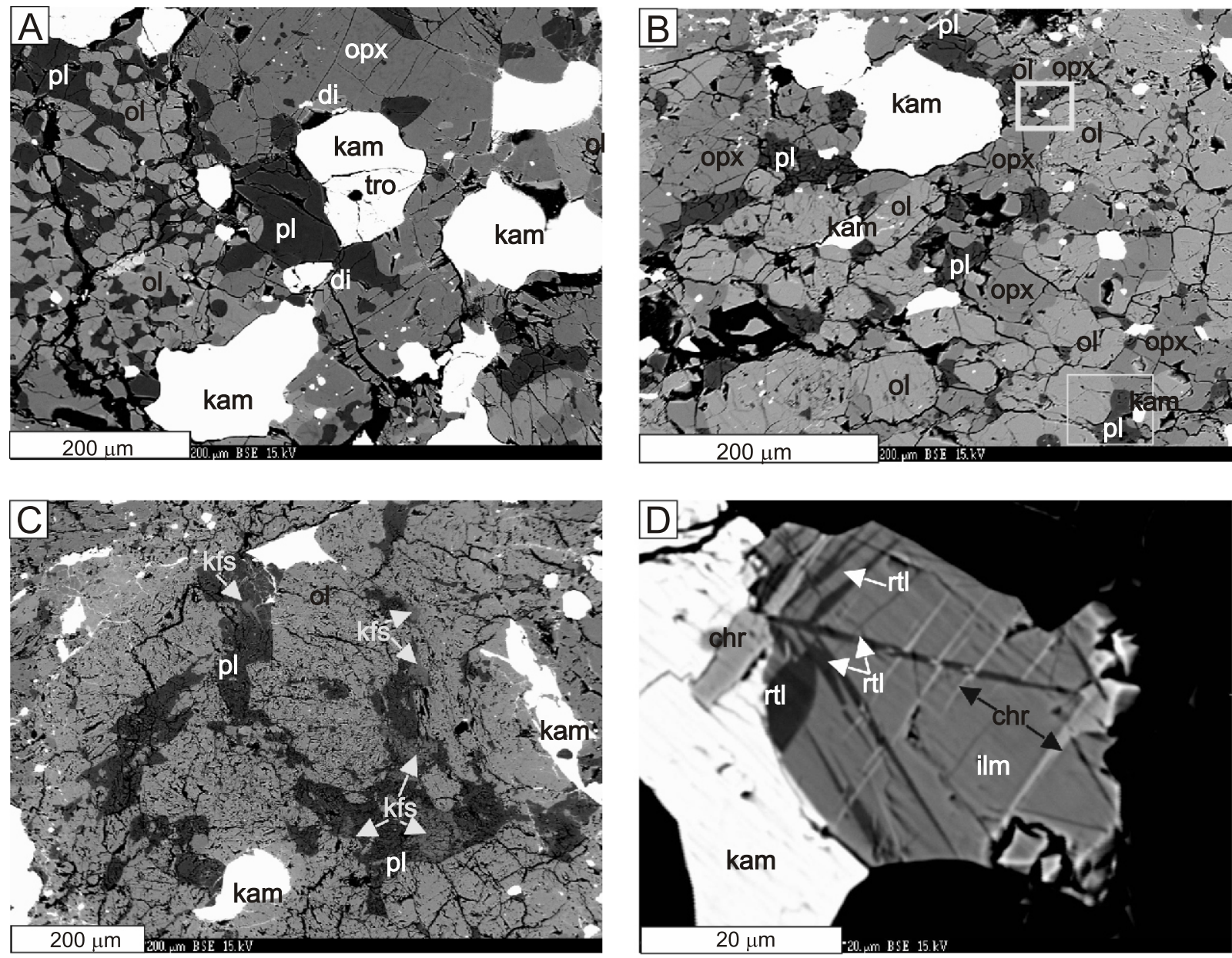

Fig. 8. Equilibrated $\mathrm{H} 6$ type clast with obliterated chondritic texture

A - textures of recrystallisation (right-hand side) and partial melting (left-hand side); large, likely skeletal plagioclase grains are interstitial to rounded olivine and pyroxene and encapsulate kamacite-troilite aggregates (left part), by contrast, the recrystallised-only part (righ-hand side) is composed of large olivine and pyroxene grains, BSE image; B - recrystallised, re-equilibrated texture of clast; large kamacite grain encapsulated in plagioclase suggest the influence of localized partial melting, olivine and pyroxene crystals form $\sim 120^{\circ}$ triple junctures, curving-in of olivine at contact with interstitial plagioclase (rectangles); suggests re-equilibration of crystals with partial melt, BSE image; C - potassium feldspars (kfs, arrows) forming patches at the margins of interstitial plagioclase in clast, BSE image; D - ilmenite with rutile lamella; also some chromite lamella are present, ilmenite contacts with FeNi-metal, BSE image; di - diopside, ilm - ilmenite, kfs - potassium feldspar, rtl - rutile, other explanations as in Figures 2 and 7 


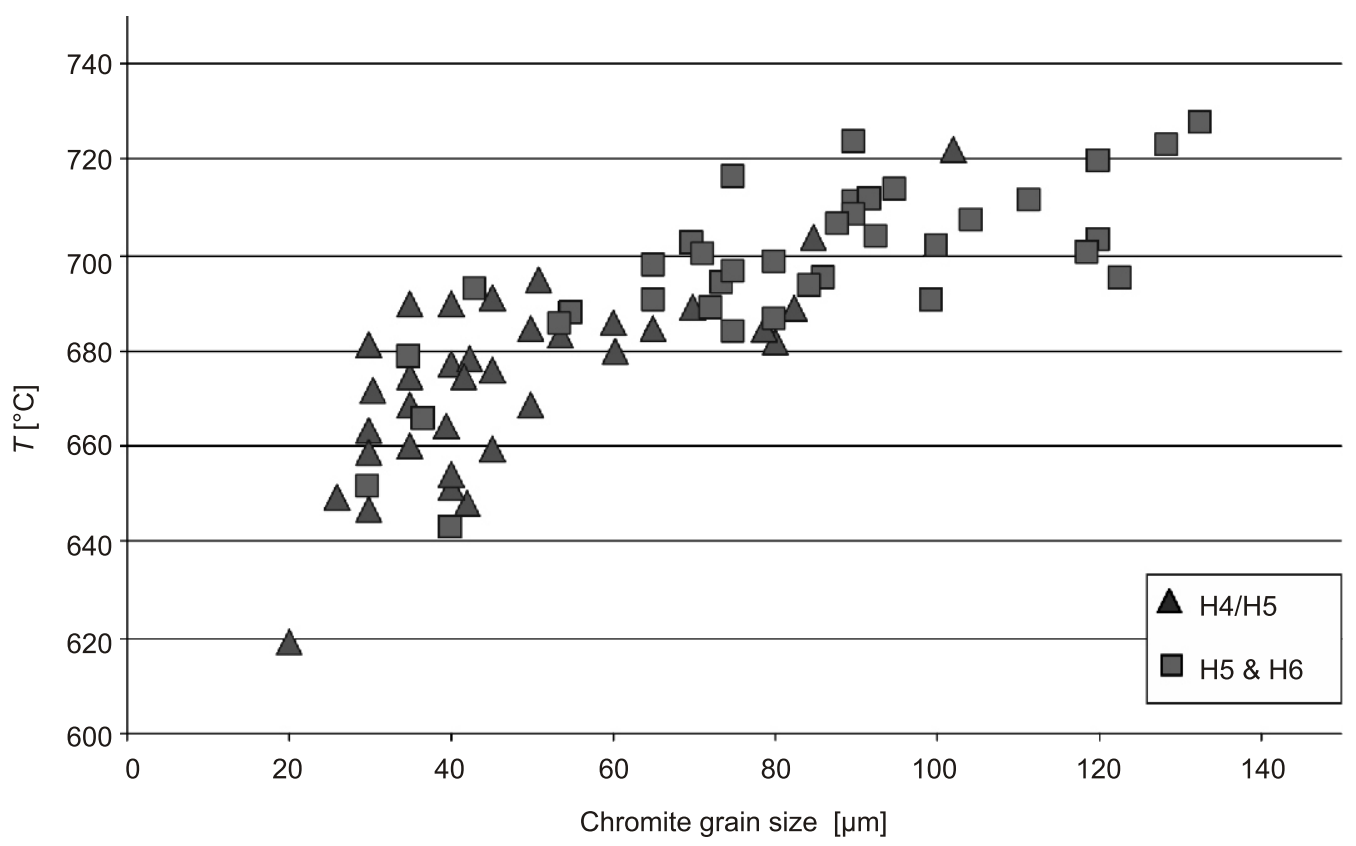

Fig. 9. Calculated olivine-spinel equilibration temperatures for the host rock and equilibrated clasts of the Pułtusk chondrite

Data are shown in correlation with the shortest dimensions of chromite grains having taken into calculation

tions were done for 35 mineral pairs in the host rock and 37 mineral pairs in the $\mathrm{H} 5$ and $\mathrm{H} 6$ clasts. Example EPM input data and thermometric calculations for olivine-chromite pairs are given in Appendix 8.

For the host rock, calculated equilibration temperature is in the range of $619-724^{\circ} \mathrm{C}$, with the most common values around $660-690^{\circ} \mathrm{C}$. Temperatures of $>700^{\circ} \mathrm{C}$ were recorded only in case of two olivine-chromite pairs (Fig. 9). Olivine and chromite in the $\mathrm{H} 5$ and $\mathrm{H} 6$ clasts provide temperatures in the range of $643-730^{\circ} \mathrm{C}$, and the most common are temperatures of $>680^{\circ} \mathrm{C}$.

Calculated equilibration temperatures in both types of material do not differ substantially. In both host rock and clasts, it is marked, however, that the equilibration temperature correlates with chromite grain size. To be precise, the larger the chromite grain size, the higher the temperature calculated (Fig. 9). The trend appears to be similar for host rock and clasts temperature calculations. The highest equilibration temperatures $\left(700-710^{\circ} \mathrm{C}\right)$ are retained by those mineral pairs in which chromite is $>80 \mu \mathrm{m}$. The lowest temperatures are always related to the mineral pairs with chromite grains $<40 \mu \mathrm{m}$. However, if chromite grains are $>90 \mu \mathrm{m}$, the trend in increase of temperature recorded appears to cease. The size of olivine seems to have no influence on the thermometry and calculations.

\section{UNEQUILIBRATED SPINEL-BEARING INCLUSIONS}

The primary feature of the tiny inclusions, causing them to be distinguished from the host rock (Table 1), is their out-of-equilibrium chemical composition and presence of zonal spinel group mineral grains (Fig. 10). The spinels occur as phenocrysts in chondrules (Fig. 10A) or as subhedral-euhedral crystals accompanied by silicates (Fig. 10B-C). Spinel-bearing chondrules are $320-450 \mu \mathrm{m}$-sized, their mesostasis is glassy or cryptocrystalline and boundaries are very distinct (Fig. 10A). Mineral aggregates are in turn 300-600 $\mu \mathrm{m}$ across, with spinel grains $60-130 \mu \mathrm{m}$-sized (in one case up to $400 \mu \mathrm{m}$; Fig. 10C) and olivine and pyroxene grains are 30-320 $\mu \mathrm{m}$-sized. The matrix of the aggregates is opaque, feldspathic (Fig. 10B). Nearly $55-70 \%$ of the matrix is microcrystalline, while the rest is glassy.

Spinel group minerals - major and minor element composition. Spinel group minerals show extremely wide compositional variations both between and inside the grains, expressed by broad ranges of atomic ratios $\mathrm{Fe} /(\mathrm{Fe}+\mathrm{Mg})(\mathrm{Fe \#})$ and $\mathrm{Cr} /(\mathrm{Cr}+\mathrm{Al})(\mathrm{Cr} \#)$. The Fe\# varies from 0.31 to 0.81 and the $\mathrm{Cr} \#$ ranges from 0.05 to 0.68 (meaning a composition from nearly pure $\mathrm{MgAl}_{2} \mathrm{O}_{4}$ to the typical host chromite). The $\mathrm{Cr} \#$ and Fe\# ratios are positively correlated with each other, and the spinel group minerals fall into field of chromian spinel $(0.2<\mathrm{Fe} \#<0.5$ and/or $0.2<\mathrm{Cr} \#<0.5)$, picotite $(0.5<\mathrm{Fe \#}<0.75$ and $0<\mathrm{Cr} \#<0.5)$ and spinelian chromite $(0.3<\mathrm{Fe \#}<0.8$ and/or $0.5<\mathrm{Cr} \#<0.8$; see Fig. 4 and Appendix 4). Since EMP measurements of these minerals gave essentially stoichiometric in composition results, ferric iron (magnetite component) is negligibly low (up to $0.55 \mathrm{~mol} \%$ of magnetite).

The spinel grains show continuous, large increase of the atomic ratios of $\mathrm{Fe \#}$ and $\mathrm{Cr} \#$ from the core to the rim parts (Fig. 10A-C). However, zonation profiles are asymmetrical for individual grains, and $\mathrm{Cr}$ and Fe\# increase in those parts of the crystals that are in contact with olivine grains or located nearest to the chondrules' boundaries (Fig. 10A, C, D). Cores of the grains are usually of chromian spinel composition (Fe\# 0.31-0.46 and Cr\# 0.05-0.26), while their rims are rather much higher in Mg and Al. At the contact with olivine, spinelian chromite composition is usual (Fe\# and $\mathrm{Cr} \#$ in the ranges $0.5-0.74$ and $0.45-0.64$, respectively), while at the contact with plagioclase, chromian spinels and picotites rather occur (Fe\# and $\mathrm{Cr} \#$ as low as $0.36-0.5$ and $0.13-0.4$, respectively; Fig. 10D; also see points at Fig. 4 and compare the data from Fig. 10A, B). It is important to note that the composition of spinel rim parts at the contact with olivine approaches the composition 

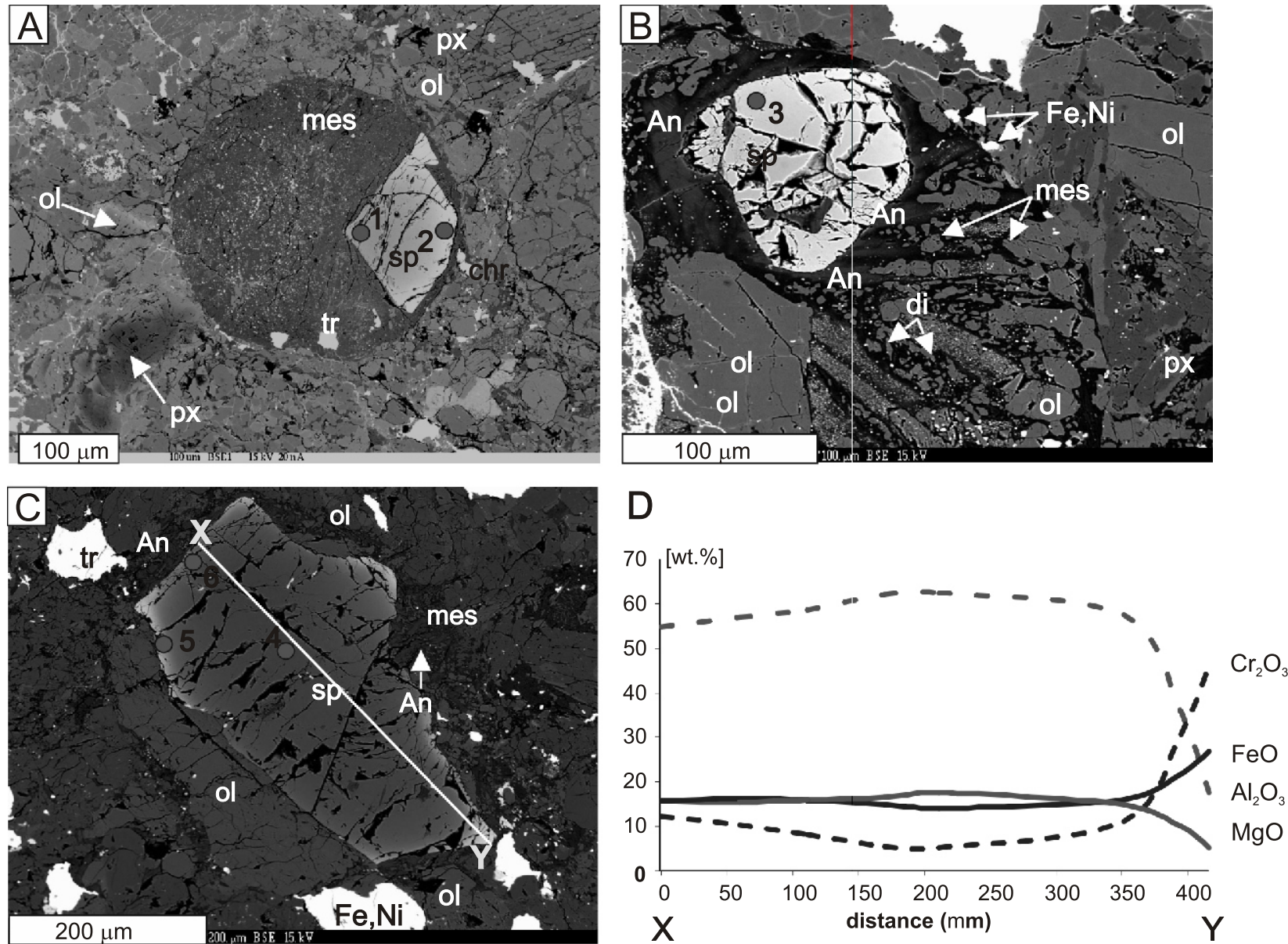

Fig. 10. Textures of spinel-bearing inclusions

A - chondrule with chromian spinel phenocryst; $\mathrm{FeO}$ and $\mathrm{Cr}_{2} \mathrm{O}_{3}$ are enriched at the grain edge i.e., towards the chondrule exterior, while $\mathrm{Al}_{2} \mathrm{O}$ and $\mathrm{MgO}$ are depleted; the chondrule mesostasis comprises a microcrystalline feldspar, olivine crystals and opaque phases: zonal olivine and pyroxene crystals in the vicinity of the chondrule are present (marked by arrows), BSE image; $\mathbf{B}$ - spinel-bearing aggregate; lath-like anorthite and Al-diopside microcrystals and albite-andesine glass embed the spinel grain; $\mathbf{C}$ - spinel-bearing aggregate; the large spinel grain reveals strong asymmetry of compositional zonation, $\mathrm{X}-\mathrm{Y}-$ compositional profile across the spinel grain shown in Figure 10D, BSE image; D - rim-to-rim zoning profile for the major elements $\mathrm{Al}_{2} \mathrm{O}_{3}, \mathrm{Cr}_{2} \mathrm{O}_{3}, \mathrm{FeO}$ and $\mathrm{MgO}$ across the zoned spinel grain in the spinel-bearing inclusion; extreme compositional asymmetry is evident, as the part of spinel being in contact with olivine crystals (profile end $\mathrm{Y}$ ) is rich in $\mathrm{Cr}_{2} \mathrm{O}_{3}$ and $\mathrm{FeO}$, while the other crystal edge contacts with plagioclase-rich matrix (profile end $\mathrm{X}$ ), BSE image; numbers in BSE images relate to point analyses in zonal spinels, the atomic ratios Fe\# and Cr\# of which are shown in Figure 4, point analyses indicate the asymmetrical zonation of spinel group minerals; An - anorthite-rich plagioclase, FeNi - iron-nicke metal alloys, mes - glassy mesostasis, px - low-Ca pyroxene, sp - Mg,Al-rich spinel, other explanations as in Figures 2, 4 and 7

of individual spinelian chromite grains in the host rock, those that revealed lower Fe\# and $\mathrm{Cr} \#$ ratios than typical host chromites (Fig. 4 and Appendix 4).

Spinel group minerals always contain minor amounts of $\mathrm{TiO}_{2}$ (0.13-2.35 wt.\%), $\mathrm{MnO}\left(0.291 .05\right.$ wt. \%), and $\mathrm{V}_{2} \mathrm{O}_{3}$ (0.29-0.86 wt.\%), the contents of which generally correlate with major element patterns. They also contain significant amounts of $\mathrm{ZnO}(0.15-0.62 \mathrm{wt} . \%)$, the content of which, however, is not compatible with major elements (Appendix 4).

Composition of silicates in the inclusions. The mean composition of olivine (17.6 mol\% Fa), as phenocrysts in spinel-bearing chondrules and grains in spinel-bearing aggregates approaches the composition of olivine grains in the Pultusk host (Fig. 3A, compared to Fig. 3B and Appendix 1). However, some olivine grains accompanying the spinels retain zonation (Fig. 10A), with a broad compositional range of 6.9-30.2 mol\% Fa (Fig. 3A). Disequilibrium of olivine is well-expressed by a standard deviation value of $3.6 \mathrm{~mol} \% \mathrm{Fa}$. Stan- dard deviation of Fa content in olivine expressed as a percentage of the mean value (PMD parameter defined by Sears and Dodd, 1988 and used below for classification) gives value of $20.5 \mathrm{~mol} \%$. Olivine contains minor amounts of $\mathrm{MnO}$ of $0.42-0.55$ wt. $\%$ and, in some cases, $\mathrm{Cr}_{2} \mathrm{O}_{3}$ above EMP detection limit (0.12-0.26 wt.\%; Appendix 1).

Low-Ca pyroxene has mean composition $\mathrm{En}_{82.4} \mathrm{Fs}_{16,1} \mathrm{Wo}_{17}$ but grains are usually zonal in composition. Zonality relates to all the major elements: $\mathrm{Fe}, \mathrm{Mg}$ and $\mathrm{Ca} ; 7.7-17.1 \mathrm{~mol} \% \mathrm{Fs}$ and 0.3-3.2 mol\% Wo). As minor enrichments, pyroxene contains $\mathrm{MnO}$ (0.17-0.53 wt.\%) and $\mathrm{Cr}_{2} \mathrm{O}_{3}(0.10-0.35$ wt. \%; Appendix 2).

Feldspathic mesostasis of spinel-bearing chondrule and the matrix-forming glass in inclusions is of composition of albite-andesine $A b_{61.5-87.1} A n_{9.3-36.0} \mathrm{Or}_{2.2-5.4}$ (Fig. 6 and Appendix 7). The small crystals of anorthite-bytownite $\left(\mathrm{Ab}_{16.1-57.1} \mathrm{An}_{41.4-83.7} \mathrm{Or}_{0.2-1.5}\right)$ and Al-diopside $\left(\mathrm{En}_{47.6} \mathrm{Fs}_{5.5} \mathrm{Wo}_{46.9}\right.$; enriched in refractory elements: 5.82 wt. $\% \mathrm{Al}_{2} \mathrm{O}_{3}, 1.04-2.62 \mathrm{wt} \% \mathrm{TiO}_{2}$ and up to 1.75 wt. $\% \mathrm{Cr}_{2} \mathrm{O}_{3}$; Appendix 3) are embedded into the glass (Fig. 10B). 
Opaque minerals composition. Opaque minerals accompanying spinels in inclusions are troilite and zoneless taenite (20.62-35.86 wt.\% Ni). Cobalt content in taenite varies substantially from grain to grain (0.03-1.04 wt.\%; Fig. 5 and Appendix 6). One individual kamacite grain was additionally found in inclusions and its $\mathrm{Ni}$ and $\mathrm{Co}$ contents were measured as 4.48 wt. $\%$ and 0.48 wt. $\%$, respectively. The measured Co content is low as compared with the minerals in the host rock and clasts. In contrast to the host grains, FeNi-metal grains in spinel-bearing inclusions do not reveal any correlation for Co and Ni (Fig. 5 and Appendix 6).

\section{DISCUSSION}

The Pultusk meteorite breccia contains fragments of unequilibrated and highly equilibrated material, assembled altogether. Analysis of the breccia gives an opportunity to reconstruct the thermal evolution of individual clasts. Comparison of this record with standard petrological classification (Van Schmus and Wood, 1967) of the same material shows inprecision the classificatory parameters reflect accretional metamorphic conditions affecting the meteorite on its parent body.

\section{STANDARD PETROLOGICAL CLASSIFICATION OF THE PUŁTUSK CHODNRITE}

Host rock of H4/H5 type. Well-distinguished chondrules, their sharp boundaries, preserved glassy mesostasis and matrix, and only some tiny plagioclase grains in the Pultusk host rock (Fig. 2A-C) are the features typical for rock of type 4 in the Van Schmus and Wood (1967) classification. These features agree with the monoclinic structure of the low-Ca pyroxenes (Fig. 2B) and with the wide, but well-clustered compositional range of $\mathrm{Fa}$ content in the olivine (Fig. 3B). Polysynthetic twinning observed in some pyroxene crystals might in principle result also from transformations driven by a later shock event. However, in the Pultusk host rock the record of weak-moderate shock suggests that shock pressures were not sufficient to have led to such transformation (e.g., Stöffler et al., 1991), thus the feature is related to accretional metamorphism.

The host rock is, however, not texturally homogeneous, and based on the plagioclase grain size and the blurring of chondrule boundaries (Fig. $2 \mathrm{C}$ vs. D), some parts of the host represent rather type 5 , which is in agreement with earlier observations (Binns, 1968; Manecki, 1972; Siemiątkowski, 2004). The textural differences are not accompanied by any mechanical boundaries (which rules out a clastic origin), and unambiguous distinction between $\mathrm{H} 4$ and $\mathrm{H} 5$ rock is problematic, even at the scale of individual specimens.

Equilibrated clasts $\mathrm{H} 5$ and $\mathrm{H6}$. The clasts represent well-equilibrated and recrystallised material of high petrologic types in the Van Schmus and Wood (1967) classification. This is confirmed by the narrow compositional ranges of very well-equilibrated olivine grains (Fig. 3C) as well as by systematic increase (as compared to the host rock) of $\mathrm{Ni}$ in tetrataenite, decrease of $\mathrm{Ni}$ content in kamacite (Fig. 5), and observed straightening of boundaries of FeNi-metal grains (Figs. 7B and 8A; Gattacceca et al., 2014; Guignard and Toplis, 2015).

The study presented in this paper shows that clasts, despite being compositionally very similar, differ greatly texturally with each other. Clasts with preserved relict chondrules and plagioclase grains up to $40 \mu \mathrm{m}$ in size (Van Schmus and Wood, 1967) reflect type 5 material (Fig. 7A), while clasts with almost obliterated chondritic textures and plagioclase crystals $>50 \mu \mathrm{m}$ are rather of type 6 (Fig. 8A, B).

The features of interstitial plagioclase (Fig. 8A-C) may suggest that the material in type 6 rock was affected by very initial partial melting (see discussion below). If more advanced, the record of partial melting would allow classification of the particular Pultusk clasts as of type 7 (Tait et al., 2014). However, the orthopyroxene lacks exsolution of Ca-pyroxene, and only minor increase of Ca content in the low-Ca pyroxene is observed (Appendix 2), suggesting partial melting was not so evolved. In support of this, the networking of interstitial plagioclase in clasts is limited and only weak zonation of plagioclase is observed.

Unequilibrated H3.8 material. The composition of the minerals in spinel-bearing inclusions in the Pultusk chondrite suggests they have not reached the metamorphic conditions typical of the $\mathrm{H} 4$ type. This corresponds well to the sharply outlined chondrules, and the occurrence of glassy-microcrystalline matrix preserving anorthitic lamellae (Sears and Dodd, 1988).

The inclusions in the Pultusk chondrite are ascribed to the 3.8 subtype, according to classification of Sears and Dodd (1988), based on the 20 mol\% Fa value of percent mean deviation in olivine (i.e., standard deviation expressed as a percentage of the mean; Fig. 10A) and the prevalence of finely crystalline matrix material. Due to the limited size of the inclusions, only 6 point analyses were taken of FeNi-metal grains, and only one of these reports the composition of kamacite (Fig. 5 and Appendix 6). Thus, the results obtained cannot provide quantitative information on the spread of cobalt content in the kamacite (Sears and Dodd, 1988), which is the classificatory parameter. However, it is known that increase in petrologic subtype links to cobalt redistribution, precisely to increase of Co content in kamacite and its decrease in taenite (e.g., Rubin, 1990; Kimura et al., 2008). Given the qualitatively, significantly higher Co amount in taenite and the lower Co content in kamacite in inclusions as compared to the host taenite (Fig. 5) agrees with the petrologic subtype 3.8 of the inclusions.

Assuming that the attaining of equilibrium by silicate minerals on a chondritic parent body needs interdiffusion processes with oxide minerals (Bunch et al., 1967; Matsunami et al., 1990), spinel group minerals should also provide classificatory parameters (e.g., Grossman and Brearley, 2005). It is known that the content of major and minor (especially $\mathrm{ZnO}$ ) oxides in spinel group minerals becomes more homogeneous with increasing petrologic subtype, and that the average atomic ratio $\mathrm{Fe} /(\mathrm{Fe}+\mathrm{Mg})$ generally increases in spinels (Johnson and Prinz, 1991; Kimura et al., 2006). Spinel group minerals of the Pultusk inclusions reveal rather low major element atomic ratios (see Fe\# in Figs. 4 and 10; Appendix 4) and broad ranges of contents of minor oxides like $\mathrm{TiO}_{2}, \mathrm{~V}_{2} \mathrm{O}_{3}$, and $\mathrm{ZnO}$. Comparing Pultusk spinel compositions to compositions of similar objects in other H chondrites (Fudali and Noonan, 1975; Kimura et al., 2002), a classification of the inclusions as type 3.8 is reasonable. Accordingly, olivine of the Pultusk inclusions is quite rich in $\mathrm{Cr}_{2} \mathrm{O}_{3}$. Compared to the results of Grossman and Brearley (2005), the olivine composition would suggest an even lower petrologic subtype of the Pultusk inclusions i.e., subtype 3.5-3.6.

TEXTURAL AND COMPOSITIONAL PROPERTIES OF THE PUŁTUSK CHONDRITE BEYOND ITS PETROLOGICAL CLASSIFICATION

The simplest inference resulting from the above classification of the Pultusk chondrite and from definition of the classification scheme itself (Van Schmus and Wood, 1967) should be that the clasts of higher petrologic type experienced more ad- 
vanced thermal metamorphism than the host material of lower type. More precisely, the higher the petrologic type, the higher peak temperatures attained during metamorphism. Taken all together, however, the textural and compositional features of the Pultusk clearly do not correlate with each other and the textural/compositional maturity does not evolve with the temperature ranges attained.

The aspects inexplicable by increase of peak metamorphic temperature solely are:

- the lack of considerable differences in silicate and oxide composition in the host and clast rock, compared with the observed differences in textures that the minerals occur in (see Fig. 2 vs. Figs. 7 and 8);

- the lack of substantial differences in olivine-chromite equilibration temperature for type 4 host material and type 5 and 6 chondritic clasts (see Fig. 9), mandatory to raise the observed textural differences if the temperatures are assumed to be peak metamorphic values;

- the presence of patchy alkali feldspar crystals and ilmenite-rutile associations in type 6 only material (Fig. 8), taking into account that both are known to be products of low- rather than high temperature processes;

- the textural inhomogeneity of the host rock at small scale (i.e., ambiguous classification as type 4/5; see Fig. 2);

- the preservation of tiny unequilibrated spinel-bearing inclusions in the host material (with no clastic origin; Fig. 10) and an observed general continuous trend of compositions of spinel group minerals in inclusions and host (Fig. 4).

THERMAL METAMORPHIC HISTORY OF THE PUŁTUSK BRECCIA

Interpretation of olivine-chromite equilibration temperatures. Olivine-chromite thermometric calculations in the Pultusk host rock and clasts of type 5 and type 6 provide values close to each other $\left(620-720^{\circ} \mathrm{C}, 640-730^{\circ} \mathrm{C}\right.$, respectively). If the temperatures calculated had represented peak metamorphic values, the metamorphic conditions would not have been sufficiently different to cause the textural differences observed (Fig. 9). The olivine-chromite closure temperatures form broad, imprecise ranges of values and these appear to correlate with spinel grain size. A likely explanation is that, after attaining peak temperatures, chromite re-equilibrated with olivine during cooling, the mechanism proposed earlier to take place during the thermal evolution of $\mathrm{H}$ chondrites (Kessel et al., 2007). The model substantiates that the tiniest chromite grains re-equilibrated easily with decreasing temperatures during cooling, while the largest crystals impeded re-equilibration and preserved equilibration state attained in higher temperatures. The conclusion coming from this scenario is that the host $\mathrm{H} 4 / \mathrm{H} 5$ attained a peak metamorphic temperature of at least $\sim 720^{\circ} \mathrm{C}$ and clasts of type 5 and type 6 were metamorphosed at temperatures higher than $\sim 730^{\circ} \mathrm{C}$, and the real values might have been much higher. After the peak conditions, the rock must have slowly cooled down to $\sim 620^{\circ} \mathrm{C}$.

A model of two-phase metamorphism, inferred from interpretation of the olivine-chromite closure temperatures, is capable of accounting for apparent textural and compositional inconsistencies in the Pultusk breccia, these being beyond petrological classification.

Progressive metamorphism and attaining the peak temperature. A progressive metamorphic phase accounts for textural maturation of the clasts, such as the formation of triple junctions between silicates in type 5 and 6 clasts in the Pultusk chondrite (Figs. $7 \mathrm{~B}$ and $8 \mathrm{~A}, \mathrm{~B}$ ). The temperature of $\sim 720-730^{\circ} \mathrm{C}$, as inferred above, was sufficient to conclude the compositional homogenization of the main silicate minerals in the host rock and clasts (Huss et al., 2006; Kovach and Jones, 2010). In particular it explains well that the compositions of feldspathic mesostasis and plagioclase are constant through the Pultusk host and all the clasts (Fig. 6 and Appendix 7). This implies that the temperatures were high enough for glass composition homogenization in the early evolution of the parent body. It also suggests that diffusion of elements affected the mesostasis glass rather than the plagioclase and that the latter crystallised further from the glass that had already compositionally equilibrated.

Strong evidence exists that type 6 clasts experienced much higher temperatures than recorded by olivine-chromite pairs i.e., $\sim 1000^{\circ} \mathrm{C}$. The shape of the plagioclase grains in type 6 clasts suggests they formed localized networks of skeletal crystals crystallised between olivine and pyroxene grains (Fig. 8A-C). The association of enlarged FeNi-metal and troilite grains encapsulated in plagioclase (Fig. 8A, B) implies that both phases were once in a liquid state (Tait et al., 2014). Those textures suggest the onset of partial melting in the rocks. The temperature required to melt conjoined grains of troilite and metal of $\mathrm{H}$ chondrite composition is $\sim 960^{\circ} \mathrm{C}$ (Tomkins, 2009), and silicate partial melting commences at $\sim 1050^{\circ} \mathrm{C}$ (e.g., Dodd, 1969; Takeda et al., 1984). It is, however, important to note that textures of partial melting are localized in the Pultusk chondrite, thus temperatures were likely not higher than those required for the onset of partial melting. Supporting evidence comes from rutile-ilmenite associations in type 6 materials (Fig. 8D). Since ilmenite is associated with kamacite, the associations are most likely a product of the breakdown of pseudobrookite-armalcolite (Buseck and Keil, 1966; Kimura et al., 1991), this mineral becoming highly unstable in cooling below $1140^{\circ} \mathrm{C}$.

Peak temperatures of $\sim 1000^{\circ} \mathrm{C}$ for the Pultusk type 6 clasts agree well with the calculations of two-pyroxene equilibration temperatures obtained for other $\mathrm{H} 6$ chondrites by Harrison and Grimm (2010).

Retrograde metamorphism. There are several lines of evidence that prograde metamorphism in the Pultusk material was followed by a retrogressive phase. Common re-equilibration of olivine and chromite down to temperatures of $\sim 620^{\circ} \mathrm{C}$ suggests that retrogression affected all the types of chondritic material in the Pultusk parent body. The record of retrogression is, however, best preserved in type 6 clasts, where cooling rates most likely were the slowest. In these clasts slow retrogression is recorded by curving-in of olivine grains at the contact with plagioclase (Fig. 8B), likely due to grain boundary re-equilibration with partial melt. Patchy crystallisation of potassium feldspar (Fig. 8C) from partial plagioclase melt is probably related to fractionation during growth (Takeda et al., 1984; Friedrich et al., 2014), a process which closes at $\sim 600^{\circ} \mathrm{C}$, according to the feldspar phase diagram. Moreover, pseudobrookite-armalcolite breakdown to ilmenite and rutile, which is considered to have occurred in type 6 Pułtusk material, requires slow cooling down to $\sim 700^{\circ} \mathrm{C}$ (Buseck and Keil, 1966; Hayob and Essene, 1995).

There are no distinct compositional or textural features in any petrologic type material in the Pultusk chondrite providing information on cooling rate below $600^{\circ} \mathrm{C}$, suggesting that at this stage cooling was rather rapid.

Early impact event as a trigger for two-phase metamorphism. The two-phase metamorphism inferred requires a heat source on the Pultusk parent body energetic enough to provide high peak temperatures and at the same time sufficiently constant to sustain the long-lasting retrograde activity. For chondritic parent bodies two heat sources are recognized: de- 
cay of short-lived radionuclides, notably ${ }^{26} \mathrm{Al}$ (e.g., Miyamoto et al., 1981; Trieloff et al., 2003; Bouvier et al., 2007) and collisions between planetesimals (e.g., Rubin, 1995; Davison et al., 2013; Ciesla et al., 2013). The former is capable of maintaining a relatively long metamorphic episode, but is not energetic enough to lead to high temperature increase (in the case of Pultusk $\sim 1000^{\circ} \mathrm{C}$ is required), while the latter source, exactly the opposite, leads to rapid high temperature increase and similarly rapid quenching. Thus, the only reasonable cause for the introduction of two-phase metamorphism of the chondritic parent body of Pultusk may be juxtaposition of both processes i.e., an impact event affecting a body that was being internally heated. In such a scenario, rapid post-impact temperature rise might have led to increase of peak metamorphic temperature in the chondrite, but later temperature changes (i.e., decrease after impact cessation) were controlled by persistent, static conditions. Partial melting in the Pultusk type 6 rock was very localized, indicating that the peak temperature was attained locally, more or less instantly and that peak conditions must have been relatively short-term. The plausibility of this scenario is supported by experimental work (Davison et al., 2013; Ciesla et al., 2013), which showed that impact processes on a warm chondritic parent body dramatically changes thermal conditions around the target point but following post-impact thermal equilibration leads to systematic, pervasive thermal modifications of the impacted body.

It is important to note that the results of the study presented here neither provide evidence for early disruption of the $\mathrm{H}$ chondrite parent body, nor exclude it. The cooling rate of the type 6 Pultusk material was much slower than that of type 5 and 4 , slow enough to cause breakdown of unstable phases and formation of potassium feldspar patches, which might have been achieved due to the location of type 6 material in the deepest parts of the parent body during cooling, in agreement with an onion-shell model. On the other hand, this may have also been a result of the location of type 6 rocks deep in the crater basement, while other types of material moved onto the surface of the parent body during the cratering event. Such material movement is in agreement with the results of Scott et al. (2014) and Ganguly et al. (2013), who suggested that the $\mathrm{H}$ chondrite material of different petrologic types must have been randomly mixed before the parent body cooled below $500^{\circ} \mathrm{C}$. Brecciation of the Pultusk chondrite, and particularly the location of type 5 and 6 fragments as clasts in dark-coloured cataclastic zones, which were formed in late impact deformation (Krzesińska, 2011; Krzesińska et al., 2015), suggests that the breccia material was re-arranged many times on the parent body, and probably not during its early evolution.

Although the metamorphic history of the Pultusk breccia is probably not representative of entire $\mathrm{H}$ chondrite parent body, it provides an additional piece of evidence in support of impact as an appealing heat source in the early thermal evolution of this body.

Influence of the primary composition of minerals. The textural inhomogeneity of the Pułtusk host rock reveals the role of some local factors in metamorphism. The most important question arises regarding the preservation of inclusions classified as H3.8 type, as coexistence of homogeneous silicates and chromite together with other, strongly heterogeneous spinel group minerals is generally permitted within a framework of standard chondritic metamorphism.

The textures and composition of spinel-bearing inclusions indicate that the minerals there had never attained chemical equilibrium. However, the lack of equilibrium seems to mostly result from the primary composition of the minerals.
It is likely that the spinel grains retained in the Pultusk chondrite as inclusions represent one of the earliest Solar System solids (Bischoff and Keil, 1984), formed in the nebula before iron-magnesium minerals had started to crystallise (Bischoff and Keil, 1984; MacPherson and Huss, 2005) and they became agglomerated into the Pultusk parent body along with typical Fe-Mg minerals. The difference in primary composition of the accreted minerals must have had consequences during the subsequent metamorphism, as partitioning of $\mathrm{Fe}^{2+}$ and $\mathrm{Mg}^{2+}$ between olivine and spinel is dependent on temperature, but also on the $\mathrm{Cr} / \mathrm{Al}$ ratio in spinel (Wlotzka, 2005; Suzuki et al., 2005). As a result, Fe-Mg exchange was slower in the case of Al-rich spinels than it was for $\mathrm{Cr}$-rich chromites. Consequently, chromites equilibrated with silicates more easily and rapidly than spinels sensu stricto, and the latter were easily preserved. Obviously, during a strong metamorphic event, all the spinel group minerals, regardless of their primary composition, would have equilibrated. This is for instance shown by the preservation of some grains of spinelian chromite composition in $\mathrm{H} 4 / \mathrm{H} 5$ rock (Fig. 4), compared with the complete lack of such grains in $\mathrm{H} 5$ and $\mathrm{H} 6$ clasts.

In the case of the Pultusk inclusions, spinel group minerals were certainly metamorphosed after being assembled in the host, as they retain asymmetrical zonation, with the asymmetry being strictly dependent on the composition of the minerals at the contacts (Fig. 10). The inclusions, despite being unequilibrated, certainly were affected by metamorphic temperatures of $\sim 720^{\circ} \mathrm{C}$, as was the host rock.

\section{CONCLUSIONS}

1. The Pułtusk chondrite breccia comprises material representing an entire suite of petrologic types. It should be classified as a H3.8-6 chondrite. Unequilibrated H3.8 type material, recognized and documented in the Pultusk breccia for the first time, is preserved as tiny inclusions in $\mathrm{H} 4$ host rock. Highly equilibrated $\mathrm{H} 5$ and $\mathrm{H} 6$ type material was brought as clasts and embedded in the breccia among products of impact deformation.

2. The metamorphic thermal evolution of the Pultusk breccia is much more complicated than its petrological classification suggests. Metamorphic conditions were only partly a function of peak temperatures achieved by different parts of the breccia but equilibrium was approached also owing to the primary composition of the minerals and the cooling rates.

3. H3.8 material in Pultusk, although compositionally unequilibrated, bears a record of metamorphic interdiffusion processes involving silicate and oxide minerals assembled in the rock. Spinel-group minerals composing the inclusions reveal strong compositional zonation and asymmetry strongly correlated to the composition of the surrounding minerals.

4. Local preservation of H3.8 inclusions is a result of the primary composition of the accreted material. Al,Mg-spinels equilibrated less efficiently with silicates than did the $\mathrm{Cr}$,Fe-chromites, even if they were reprocessed at the same metamorphic temperatures.

5. Accretional metamorphism recorded in the Pultusk meteorite is shown to occur in two phases. First, a progressive phase was related to temperature increase and led to different chemical and textural equilibration. The peak metamorphic temperatures were at least $\sim 720^{\circ} \mathrm{C}$ for the host rock, as revealed by olivine-spinel thermometry and supported by texture. For $\mathrm{H} 6$ type material, peak temperatures might have reached $\sim 1000^{\circ} \mathrm{C}$, as these are values required for the onset of partial melting of plagioclase and metal-troilite, the process recorded in the tex- 
tures of those mineral assemblages. Such temperature ranges were also required for the formation of pseudobrookite-armalkolite, which is shown to have been present in type 6 Pultusk clasts.

6. After the peak metamorphic temperatures were attained, retrograde metamorphism played a role. It led to compositional re-equilibration of the main silicates and oxides and textural equilibration of relic solid minerals with cooled partial melts in type 6 material. Cooling rate was the slowest in type 6 clasts, where it was slow enough to trigger formation of potassium feldspar patches in Na-plagioclase. The process must have lasted for a long time and supported breakdown of pseudobrookite-armalcolite to the ilmenite and rutile observed. The most likely cause of inducing retrogression and sustaining slow cooling was an early impact event on to a warm parent body.

Acknowledgements. I wish to express my gratitude to $\mathrm{Dr}$ R. Orłowski for his help in microprobe data collection, and for lively discussions from which this work benefited greatly. Drs P. Konečný, I. Holický and V. Kollárová (Bratislava) and Dr.
P. Dzierżanowski (Warsaw) are thanked for their kind assistance with electron microprobe analyses. The reviewers, Prof. Ł. Karwowski, Prof. M. Kimura, Prof. T.A. Przylibski and the Editor, Prof. T. Peryt are thanked for their comments and suggestions, which helped to improve the manuscript. Special thanks are addressed to Curators of meteorite collections, who generously donated samples of the Pultusk meteorite for study. Samples come from the collections of the S.J. Thugutt Geological Museum of the Faculty of Geology (University of Warsaw); the Geological Museum at the Institute of Geological Sciences PAS in Kraków; the Museum of the Earth, Polish Academy of Sciences in Warsaw; the Mineralogical Museum at the University of Wrockaw; and the Museum of Geological Sciences at the Jagiellonian University in Kraków. Samples were also donated to the Institute of Geological Sciences PAS from the private collections of Prof. Dr. M. Lewandowski and A. Pilski. The research was supported by the grant N N307 474838, funded by the Polish Ministry of Science and Higher Education (National Center of Science).

\section{REFERENCES}

Binns, R.A., 1968. Cognate xenoliths in chondritic meteorites: Examples in Mezö-Madaras and Ghubara. Geochimica et Cosmochimica Acta, 32: 299-317.

Bischoff, A., Keil, K., 1984. Al-rich objects in ordinary chondrites. Geochimica et Cosmochimica Acta, 48: 693-709.

Bogard, D.D., 2011. K-Ar ages of meteorites: clues to parent-body thermal histories. Chemie der Erde, 71: 207-226.

Bouvier, A., Blichert-Toft, J., Moynier, F., Vervoort, J.J., Albaréde, $\mathrm{F} ., 2007$. $\mathrm{Pb}-\mathrm{Pb}$ dating constraints on the accretion and cooling history of chondrites. Geochimica et Cosmochimica Acta, 71: 1583-1604

Brearley, A.J., Jones, R.H., 1998. Chondritic meteorites. Reviews in Mineralogy, 36: 3-1-3-398.

Bunch, T.E. Keil, K., Snetsinger, K.G., 1967. Chromite composition in relation to chemistry and texture of ordinary chondrites. Geochimica et Cosmochimica Acta, 31: 1605-1613.

Buseck, P.R., Iljima, A., 1975. High Resolution Electron Microscopy of Enstatite. II: Geological Application. American Mineralogist, 60: 771-784

Buseck, P.R., Keil, K., 1966. Meteoritic rutile. American Mineralogist, 51: 1506-1515.

Ciesla, F.J., Davison, T.M., Collins, G.S., O’Brien, D.P., 2013. Thermal consequences of impacts in the early solar system. Meteoritics and Planetary Science, 48: 2559-2576.

Davison, T.M., O'Brien, D.P., Ciesla, F.J., Collins, G.S., 2013. The early impact histories of meteorite parent bodies. Meteoritics and Planetary Science, 48: 1894-1918.

Dodd, R.T., 1969. Metamorphism of ordinary chondrites: A review. Geochimica et Cosmochimica Acta, 33: 161-203.

Friedrich, J.M., Perrotta, G.C., Kimura, M., 2014. Compositions, geochemistry, and shock histories of recrystallized LL chondrites. Geochimica et Cosmochimica Acta, 139: 83-97.

Fudali, R.F., Noonan, F., 1975. Gobabeb, a new chondrite: the coexistence of equilibrated silicates and unequilibrated spinels. Meteoritics, 10: 31-39.

Ganguly, J., Tirone, M., Chakraborty, S., Domanik, K., 2013. H chondrite parent asteroid: a multistage cooling, fragmentation and re-accretion history constrained by thermometric studied diffusion kinetic modeling and geochronological data Geochimica et Cosmochimica Acta, 105: 206-220.
Gattacceca, J., Suavet, C., Rochette, P., Weiss, B.P., Winklhofer, M., Uehara, M., Friedrich, J., 2014. Metal phases in ordinary chondrites: magnetic hysteresis properties and implications for thermal history. Meteoritics and Planetary Science, 49: 652-676.

Grimm, R.E., 1985. Penecontemporaneous metamorphism, fragmentation, and reassembly of ordinary chondrite parent bodies. Journal of Geophysical Research, 90: 2022-2028.

Grossman, J.N., Brearley, A.J., 2005. The onset of metamorphism in ordinary and carbonaceous chondrites. Meteoritics and Planetary Science, 40: 87-122.

Guignard, J., Toplis, M.J., 2015. Textural properties of iron-rich phases in $\mathrm{H}$ ordinary chondrites and quantitative links to the degree of thermal metamorphism. Geochimica et Cosmochimica Acta, 149: 46-63.

Harrison, K.P., Grimm, R.E., 2010. Thermal constrains on the early history of the $\mathrm{H}$-chondrite parent body reconsidered Geochimica et Cosmochimica Acta, 74: 5410-5423.

Hayob, J.L., Essene, E.J., 1995. Armalcolite in crustal paragenesis xenoliths, central Mexico. American Mineralogist, 80: 810-822.

Henke, S., Gail, H.-P., Trieloff, M., Schwarz, W.H., Kleine, T., 2012. Thermal history modeling of the $H$ chondrite parent body. Astronomy and Astrophysics, 545: A135.

Huss, G.R., Rubin, A.E., Grossman, J.N., 2006. Thermal metamorphism in chondrites. Meteorites and the Early Solar System II. In: Meteorites and the Early Solar System II (eds. D.S. Lauretta and H.Y. McSween, Jr.): 567-586. The University of Arizona Press.

Irvine, T.N., 1965. Chromian spinel as a petrogenetic indicator. Part I. Theory. Canadian Journal of Earth Sciences, 2: 648-672.

Johnson, C.A., Prinz, M., 1991. Chromite and olivine in type II chondrules in carbonaceous and ordinary chondrites: Implications for thermal histories and group differences. Geochimica et Cosmochimica Acta, 55: 893-904.

Kessel, R., Beckett, J.R., Stolper, E.M., 2007. The thermal history of equilibrated ordinary chondrites and the relationship between textural maturity and temperature. Geochimica et Cosmochimica Acta, 71: 1855-1881.

Kimura, M., Ikeda, Y., Ebihara, M., Prinz, M., 1991. New enclaves in Vaca Muerta mesosiderite: petrogenesis and comparison 
with HED meteorites. Proceedings of the NIPR Symposium on Antarctic Meteorites, 4: 263-306.

Kimura, M., Hiyagon, H., Palme, H., Spettel, B., Wolf, D., Clayton, R.N., Mayeda, T.K., Sato, T., Suzuki, A., Kojima, H., 2002. Yamato 792947, 793408 and 82038: The most primitive $H$ chondrites, with abundant refractory inclusions. Meteoritics and Planetary Science, 37: 1417-1434.

Kimura, M., Nakajima, H., Hiyagon, H., Weisberg, M.K., 2006. Spinel group minerals in LL3.00-6 chondrites: Indicators of nebular and parent body processes. Geochimica et Cosmochimica Acta, 70: 5634-5650.

Kimura, M., Grossman, J.N., Weisberg, M.K., 2008. Fe-Ni metal in primitive chondrites: Indicators of classification and metamorphic conditions for ordinary and $\mathrm{CO}$ chondrites. Meteoritics and Planetary Science, 43: 1161-1177.

Kovach, H.A., Jones, R.H., 2010. Feldspar in type 4-6 ordinary chondrites: Metamorphic processing on the $\mathrm{H}$ and $\mathrm{LL}$ chondrite parent bodies. Meteoritics and Planetary Science, 45: 246-264.

Krzesińska, A., 2011. High resolution X-ray tomography as a tool for analysis of internal textures in meteorites. Meteorites: 1, 3-12.

Krzesińska, A., Fritz, J., 2014. Weakly shocked and deformed CM microxenoliths in the Pułtusk $\mathrm{H}$ chondrite. Meteoritics and Planetary Science, 49: 595-610.

Krzesińska, A., Gattacceca, J., Friedrich, J.M., Rochette, P., 2015. Impact-related non-coaxial deformation in the Pułtusk $\mathrm{H}$ chondrite inferred from petrofabric analysis. Meteoritics and Planetary Science, 50: 401-417.

Lux, Y., Keil, K., Taylor, G.J., 1980. Metamorphism of the H-group chondrites: implications from compositional and textural trends in chondrules. Geochimica et Cosmochimica Acta, 44: 841-855.

MacPherson, G.J., Huss, G.R., 2005. Petrogenesis of Al-rich chondrules: Evidence from bulk compositions and phase equilibria. Geochimica et Cosmochimica Acta, 69: 3099-3127.

Manecki, A., 1972. Mineralogical and petrological study of the Pułtusk meteorite (in Polish with English summary). Mineralogical Transactions 2: 53-65.

Matsunami, S., Nishimura, H., Takeshi, H., 1990. The chemical compositions and textures of matrices and chondrule rims of unequilibrated ordinary chondrites - II. Thier constituent and the implications for the formation of matrix olivine. Proceedings NIPR Symposium of Antarctic Meteorites, 3: 147-180.

Merlet, C., Llovet, X., Salvet, F., 2003. Electron probe microanalysis today. Practical aspects. Proceedings of the Eight European EMAS Workshop Karlsruhe: 317.

Miyamoto, M., Fuji, N., Takeda, H., 1981. Ordinary chondrite parent body: An internal heating model. 12th Lunar and Planetary Science Conference abstracts: 1145-1152.

Pellas, R., Storzer, D., 1981. ${ }^{244} \mathrm{Pu}$ fission track thermometry and its application to stony meteorites. Proceedings of Royal Society London Ser. A, 374: 253-270.
Rubin, A.E., 1990. Kamacite and olivine in ordinary chondrites: Intergroup and intragroup relationships. Geochimica et Cosmochimica Acta, 54: 1217-1232.

Rubin, A.E., 1995. Petrologic evidence for collisional heating of chondritic asteroids. Icarus, 113: 156-167.

Sack, R.O., Ghiorso, M.S., 1991. Chromian spinels as petrogenetic indicators: thermodynamics and petrological applications. American Mineralogist, 76: 827-847.

Scott, E.R.D., Krot, T.V., Goldstein, J.I., Wakita, S., 2014. Thermal and impact history of the $\mathrm{H}$ chondrite parent asteroid during metamorphism: Constrains from metallic Fe-Ni. Geochimica et Cosmochimica Acta, 136: 13-37.

Sears, D.W.G., Dodd, R.T., 1988. Overview and classification of meteorites. In: Meteorites and the Early Solar System (eds. J.F. Kerridge and M.S. Matthews): 3-31. University of Arizona Press; Tucson, Arizona.

Siemiątkowski, J., 2004. Chondryt Pułtusk: przykład meteorytowej brekcji wieloskładnikowej (H4+H5). Meteoryt, 4: 26-28.

Stöffler, D., Keil, K., Scott, E.R.D., 1991. Shock metamorphism of ordinary chondrites. Geochimica et Cosmochimica Acta, 55: 3845-3867.

Suzuki, A., Yasuda, A., Ozawa, K., 2005. Cr-Al diffusion in chromite spinel at high-pressure. EOS Trans AGU Fall Meeting, 86: V13A-0521.

Swindle, T.D., Isachsen, C.E., Weirich, J.R., Kring, D.A., 2009. ${ }^{40} \mathrm{Ar}-{ }^{39} \mathrm{Ar}$ ages of $\mathrm{H}$-chondrite impact melt breccias. Meteoritics and Planetary Science, 44: 747-762.

Tait, A.W., Tomkins, A.G., Godel, B.M., Wilson S.A., Hasalova, P., 2014. Investigation of the $\mathrm{H} 7$ ordinary chondrite, Watson 012 : Implications for recognition and classification of Type 7 meteorites. Geochimica et Cosmochimica Acta, 134: 175-196.

Takeda, H., Hutson, T.J., Lipschutz, M.E., 1984. On the chondrite-achondrite transition: mineralogy and chemistry of Yamato 74160 (LL7). Earth and Planetary Science Letters, 71: 329-339.

Tomkins, A.G., 2009. What metal-troilite textures can tell us about post-impact metamorphism in chondrite meteorites. Meteoritics and Planetary Science, 44: 1133-1149.

Trieloff, M., Jessberger, E.K., Herrwerth, I., Hopp, J., Fiéni, C., Ghélis, M., Bourot-Denise, M., Pellas, P., 2003. Structure and thermal history of the $\mathrm{H}$-chondrite parent asteroid revealed by thermochronometry. Nature, 422: 502-506.

Van Schmus, W.R., Wood, J., 1967. A chemical-petrologic classification for the chondritic meteorites. Geochimica et Cosmochimica Acta, 31: 747-765.

Wlotzka, F., 2005. Cr spinel and chromite as petrogenetic indicators in ordinary chondrites: Equilibration temperatures of petrologic types 3.7 to 6 . Meteoritics and Planetary Sciences, 40: 1673-1702. 